University of Zurich

Department of Economics

Working Paper Series

ISSN 1664-7041 (print)

ISSN 1664-705X (online)

Working Paper No. 59

\title{
Leadership and Influence: \\ Evidence from an Artefactual Field Experiment on Local Public Good Provision
}

Giovanna d'Adda

January 2012 


\title{
Leadership and Influence:
}

\section{Evidence from an Artefactual Field Experiment on Local Public Good Provision}

\author{
Giovanna d'Adda*
}

JOB MARKET PAPER

7 November 2011

\begin{abstract}
This paper studies the effect of leadership on the level and evolution of pro-social behavior using an artefactual field experiment on local public good provision. Participants decide how much to contribute to an actual conservation project. They can then revise their donations after being randomly matched in pairs on the basis of their authority and having observed each other's contributions. Authority is measured through a social ranking exercise identifying formal and moral leaders within the community. I find that giving by a pair is higher and shows a lower tendency to decrease over time when a leader is part of a pair. This is because higher-ranked pair members in general, and leaders in particular, donate more and are less likely to revise contributions downwards after giving more than their counterparts. Leadership effects are stronger when moral authority is made salient within the experiment, in line with the ethical nature of the decision under study. These findings highlight the importance of identifying different forms of leadership and targeting the relevant leaders in projects aimed at local public good provision.
\end{abstract}

\footnotetext{
* I thank Juan Camilo Cardenas, Roberto Weber, Eliana La Ferrara, Kelsey Jack, Debrah Meloso, Joshua Miller, Andreas Madestam, Michele Pellizzari, Abigail Barr and seminar participants at Bocconi University, PSE and UZH for useful comments. I am grateful to the Centro de Estudios Interdisciplinarios Básicos y Aplicados en Complejidad (CEIBA) at the Universidad de Los Andes for funding the data collection; to ASPROCIG for logistical support in the implementation of the study; and to Carolina Laverde and Maria Fernanda Pereira for their assistance in the field. Bocconi University, Via Roentgen 1, 20136 Milan. Email: giovanna.dadda@phd.unibocconi.it.
} 


\section{Introduction}

Public good provision is a crucial element for the functioning of every social group. Social dilemmas, i.e. situations in which individuals who would benefit from the provision of the public good find it costly to contribute and would prefer to free-ride on others' contributions, are common in this context and often lead to the under-provision of public goods and services. Solutions to social dilemmas relying on governmental interventions and privatization are often unfeasible, especially in developing countries, as they require prohibitive amounts of resources and institutional capacity. Groups facing social dilemmas must frequently rely on informal solutions, designed and managed by users themselves.

Leadership is a potential solution to many important cooperation problems. Aside from the formal authority and sanctioning power often held by leaders, their ability to set an example and urge action can potentially mitigate free-riding, coordinate expectations, and otherwise encourage particular behaviors among followers. The potential value of leadership is further evident in the fact that most groups, teams and organizations function with some kind of leadership structure, even when it holds little or no formal authority. This paper examines the role of leadership in promoting the provision of local public goods. In particular, it investigates whether leaders' example can lead to higher aggregate contributions to public goods, and sustain cooperation over time. Moreover, this study asks how leaders' effectiveness depends on the type of authority they hold within the group.

This paper focuses on a particular type of public good, i.e. environmental conservation. Environmental problems are of particular interest as social dilemmas, because users have no perfect knowledge of the consequences of their resource extraction choices on natural resources' rates of depletion, and this uncertainty reinforces individuals' tendency to over-exploit them. Moreover, research on how to foster conservation of common property resources can have a large impact on development and poverty reduction, as the poor rely heavily on this type of public goods - such as fresh water, pastures and forests for their livelihoods and are severely exposed to environmental shocks. Women and children are most vulnerable to under-provision of these resources, the consequences of which they bear in terms of food security and time allocation between resource collection and productive activities.

The fieldwork for this study took place in a rural area of Northern Colombia, where overexploitation of local ecosystems has led to the rapid loss of traditional sources of people's livelihood. Participants in the study were asked to make a donation to a biodiversity conservation project. They could revise their donation choices after observing the amount given by another participant, with whom they were randomly paired. The design of the study varied the leadership status of the person whose choices were observed. Leadership was defined through a collective ranking exercise, in which participants were divided in three groups - top, medium and bottom - depending on their leadership qualities along different dimensions. Using data from the experiment, it is therefore possible to observe how participants' contribution and revision choices varied depending on their own position within the ranking, on the position of their experimental partners, and on the dimension of leadership along which relative ranking was defined. 
The empirical analysis yields the following main results. First, total contribution by a pair is significantly higher when the pair includes at least one leader. This difference is driven by the fact that leaders contribute more to environmental conservation, and not by the fact that lower-ranked participants donate significantly more when paired with leaders. Higher contributions by leaders are a consequence of two mechanisms: leaders value environmental conservation more; and the same person donates on average more, the higher her relative status within the pair. This result is consistent with previous findings in the leadership literature and with the idea that higher-ranked individuals feel a responsibility as role models for lower-ranked ones.

Second, type of authority matters. In particular, aggregate contributions are on average higher when leadership is defined along the moral dimension, rather than along the formal one. This result is interpreted as evidence of the fact that environmental conservation decisions fall predominantly within the realm of ethical norms.

Third, total contribution by a pair is also more stable over time when the pair includes at least one leader. Consistent with experimental studies on public good provision, cooperation in pairs that do not include a leader tends to unravel over time, as individuals conform more strongly to others' choices when doing so entails a reduction in giving. The presence of a leader within a pair offsets this tendency, because leaders do not reduce giving when exposed to partners who donate less than they do. Once again, this pattern results from a general negative correlation between relative status and tendency to conform, which is particularly strong among leaders. This finding is consistent with sociological theories of social comparison, which claim that individuals look up on the status ladder when determining the appropriateness of their conduct.

This paper makes a series of contributions to the existing literature on leadership and social influence. First, the use of an artefactual field experiment (Harrison \& List, 2004) makes it possible for this study to investigate the effect of leadership on donations to an actual public good. The use of a real world sample has shortcomings, first of all the loss of experimental control, but allows to investigate whether leadership effects observed in the laboratory with student samples are generalizable and empirically relevant in natural and policy relevant settings.

A second contribution of this research is its focus on existing leaders. Laboratory experiments on leadership typically assign status to participants either on the basis of their performance in small tasks within the laboratory, or randomly. This approach is chosen because it allows to cleanly evaluate the effect of (exogenously assigned) status on behavior. The approach adopted in this paper is complementary, in that it makes salient within the experiment the status with which individuals are endowed on the basis of characteristics they possess outside of the experiment. In doing so, this study can assess the relationship between long term determinants of leadership and individual behavior, and the effect of naturally occurring leadership on followers' choices.

A third novel element of this paper is its analysis of different dimensions of leadership: formal, moral and traditional. Participants within the experiment were ranked according to these three types of authority, so 
that it is possible to compare the behavior of those classified as leaders and non-leaders according to different criteria. Acknowledging the potential role of different types of leadership is particularly relevant in developing countries, where formal powers often co-exist with traditional structures of authority. In these settings, it is not obvious that rules of conduct established by formal leaders will be the most influential. This study is the first attempt at comparing the effect of different forms of leadership in fostering group cooperation. Finally, the design of the experiment is such that one can observe how giving evolves over time. Existing field studies on the effect that information about others people's choices has on individuals' decisions to donate to charity typically investigate one-shot decision environments. This study complements the findings of this literature and tests their robustness in a dynamic setting.

The remainder of the paper is structured as follows. First, an overview of the relevant literature on leadership, status and pro-social behavior is presented (Section 2). Then Section 3 describes the setting and main features of the experimental design. Section 4 spells out the main hypotheses that are then tested in the empirical analysis (Section 5). A series of robustness checks is conducted in Section 6. The ability of different theoretical perspectives to account for the empirical findings is discussed, and evidence is offered in favor or against specific explanations (Section 7). A discussion of policy implications, limits to external validity and directions for further research concludes (Section 8).

\section{Related literature}

Large literatures outside economics investigate the role of high status individuals in general, and leaders more specifically, in shaping collective outcomes. In economics, the study of leadership has received considerably less explicit attention. A small number of theoretical papers explore leadership in organizations (Hermalin, 1998; Komai, et al., 2007), and a growing stream of empirical research attempts to assess whether leadership has effects on outcomes such as economic growth (Jones \& Olken, 2005), the provision of public goods (Chattopadhyay \& Duflo, 2004), and firm profitability (Malmendier \& Tate, 2009). Other empirical papers attempt to identify what characteristics or practices make good leaders (Lazear, 2010). These studies carefully document the existence of leadership effects on collective outcomes. This paper complements their findings by focusing on one particular form of leadership, i.e. leading-by-example, and by measuring its effect directly on followers' choices, rather than on variables derived from their aggregation - such as growth and type of public goods provided.

Perhaps the greatest attention to leadership in economics has been in the area of experimental economics, where a rapidly growing number of papers use simple laboratory experiments to study the effectiveness of leadership in the context of voluntary public good games. Some of these experiments consider situations in which a leader has private information regarding the benefit obtained by provision of a public good (Potters, 2007), as in theoretical models by Hermalin (1998) and Vesterlund (2003). In the experiments, informed first-movers are able to influence the behavior of subsequent contributors. Other experiments consider situations in which there is no informational asymmetry, to study whether the presence of a first-acting leader can influence followers' contributions and increase public good provision. In general, 
these studies find that high contributions by leaders induce higher contributions by followers (Moxnes \& Van der Hejden, 2003; Gächter \& Renner, 2003) and nicely demonstrate the role of leaders in overcoming free-riding and coordination issues in social dilemmas. Most laboratory experiments induce status randomly, using small tasks or manipulating information within the laboratory. This paper takes a complementary approach, in that it wishes to explore the effect of already existing leadership on the behavior of leaders and followers. Moreover, by making salient the different degrees of authority with which subjects are endowed outside the experiment, the present study can focus on longer-term determinants of leadership.

Field experiments on leadership are rare, as they face the key methodological issue of endogeneity between selection into leadership and leader's performance. Studies that combine laboratory and field evidence find that local leaders' behavior is correlated with community members' contributions to public goods (Beekman et al., 2011; Kosfeld \& Rustagi, 2011). Non-experimental studies of community-driven development underline the role of local leaders and elites in shaping the outcomes of development projects (Mansuri \& Rao, 2004). Field studies and experiments on common pool resources show that communication, monitoring and sanctioning are effective in enforcing sustainable management systems among user groups (Cardenas \& Carpenter, 2008), especially when management institutions and their leaders are chosen by users themselves (Ostrom, 2002). The present study contributes to these strands of the literature by examining what dimensions of authority are associated with leaders' effectiveness.

While not explicitly about leadership, two further strands of the literature are close in spirit to this study. Theoretical and empirical research on social networks investigates influence within groups as a function of the position, number and type of links that individuals have within the network (Jackson, 2008; Padgett and Ansel, 1993). While the empirical analysis in this paper will always control for the number of social links of each participant, the focus of the present study is that of investigating the consequences of individual status, rather than its sources. Research on charitable giving shares this focus, and features a handful of field experiments in which donations are found to increase following the observation of others' contributions, especially if lead donators are high status individuals (e.g., Shang \& Croson, 2009; Frey \& Meyer, 2004; Alpizar \& Martinsson, 2010). This paper observes how leaders and followers' tendency to conform to each other's choices evolves over time, and, by doing so, tests the findings of the charitable giving literature within a dynamic decision environment.

\section{Setting and design}

\subsection{Setting}

A total of 251 individuals from 8 villages took part in the study. The villages are located in different municipalities of the province of Monteria, in the Northern Coast of Colombia. They are similar in terms of economic and environmental characteristics. Farming and fishing are the main economic activities. Rice, maize, yam, beans and plantain are grown across the region. Flooding and droughts are both frequent causes of harvest loss. Health posts and primary schools are present in 4 and 6 of the villages respectively. Access to other types of infrastructure differs across the sample. In particular, the largest village is reached by paved 
road and piped water, while the others are not. Regardless of the type of infrastructure, participants from all the communities mention contamination of drinking water as a major issue.

A local farmers' cooperative, ASPROCIG, acted as entry point to the communities. Representatives of ASPROCIG delivered invitations to their fellow community members. Since no show-up fee was paid to encourage attendance, ${ }^{1}$ the invitation process followed a series of guidelines in order to reduce selection biases. Participants had to live in the village, be at least 18 years old and responsible for financial decisions within the household. We invited preferably the household head or the spouse and tried to limit participation to 1 person per family. An average of 20 individuals, from a minimum of 18 to a maximum of 27 , participated to 12 experimental sessions. ${ }^{2}$

\subsection{Design}

Each session involved a ranking exercise, the mapping of the social network, a decision stage and an individual survey. An experimenter conducted the session, read out the instructions and answered questions from participants. Two assistants helped with the logistics and made sure that participants followed the experimental instructions. Sessions took on average three and a half hours.

\subsubsection{Ranking participants' social status}

The ranking exercise was aimed at isolating three dimensions of authority within the village: formal, moral and traditional. Formal authority concerns the dimension of social status associated with formal leadership roles and political power. Moral authority is related to respect and trust in one's ethical judgment. Finally, traditional authority refers to the qualities that anthropologists associate with leadership among indigenous societies in Latin America, e.g. the ability to speak in public and tell stories (Clastres, 1974). Isolating these types of authority allows me to assess which one is more relevant for decisions over local common resources, and thus to investigate the nature of such decisions in the study setting.

In order to isolate the different dimensions of authority, participants were presented with three hypothetical situations. The starting point for the formal authority ranking was the following: "The mayor has accepted to meet representatives from the village to discuss the most serious problems it faces (e.g. roads and drinking water). Who among you should go to talk to the mayor?". The moral authority ranking presented participants with the following choice instead: "There is a village member who is harming everybody with his behavior (e.g. contaminating the water with waste and chemicals). Who among you should go to talk to him about the harm he's doing to the community?". Finally, the traditional authority ranking was based around a third situation: "There is a municipal fair in which people from all villages are invited to tell stories, jokes and sing. Who among you should represent the community at the municipal fair?".

\footnotetext{
${ }^{1}$ ASPROCIG requested that no show-up fee should be paid. They were afraid that being paid to participate to a community meeting, which involved a decision about a common project, may lead people to always expect a private return from engaging in public initiatives.

${ }^{2} 2$ experimental sessions were run in each of the 4 largest villages in the sample. When in the same village, sessions took place over two subsequent days.
} 
Participants selected their representatives collectively for all rankings. The experimenter invited each participant to suggest someone else as representative. For each candidate, the experimenter asked remaining participants if they approved the candidature or not. If no objections were raised, a candidate would stand in front of the group, otherwise the experimenter prompted further suggestions. The experimenter solicited nominations in the most random and inclusive manner possible. As soon as the number of candidates reached one-third of participants, the experimenter interrupted the process. She asked one more time whether everyone agreed with the selection or whether more deserving candidates had been left out, and made changes according to participants' answers. This group represented the first choice as village representatives. Then the experimenter told participants that this first group would not be able to go to the meeting, and asked them to select a second group as substitutes. The process was repeated in a similar fashion for the group of substitutes. The experiment assistant recorded the order in which candidates joined the first and second group. The remaining one-third of participants went to form a third group.

The ranking process was conducted three times, once for each hypothetical situation. Their order was randomized across sessions. ${ }^{3}$ At the end of the exercise, the experimenter led a group discussion on the qualities of top-ranked individuals, for each ranking type, and recorded the answers. Finally, one between the formal and the moral authority ranking was randomly drawn to be implemented. ${ }^{4}$ Participants were then divided into groups according to it, seated in three different rows and given colored cards to mark their group assignment. First choices - members of the top group - received Orange cards; the substitutes - members of the middle group - received Blue cards; and the rest - bottom-ranked individuals - received Brown cards. Before proceeding to the decision stage, the experimenter reminded everyone of the ranking used to divide them into groups by referring to the corresponding hypothetical situation.

The ranking exercise was aimed at reproducing as closely as possible collective decision-making processes that take place during community meetings. This procedure is similar to those commonly implemented in participatory wealth rankings (Chambers, 1994). Extensive focus groups, conducted in the study area, guided the definition of the hypothetical situations used to identify each type of leaders. While the ranking process' lack of formal decision rules generates a loss of experimental control and makes the outcomes of the selection susceptible to being captured by vocal group members, research on deliberation processes in group decisions shows that inclusive information acquisition during deliberations yields accurate and informative decisions, and that deliberation processes are, under certain conditions, more critical for the achievement of such outcomes than decision rules (Lizzeri \& Yariv, 2011).

Nevertheless, the ranking procedure is likely to have induced a series of biases in the resulting classifications. By imposing the division of participants to a session in three equally sized groups for each hypothetical situation, the ranking created discontinuity in individual status. Individuals above and below the threshold were probably similar, but belonged to different status groups. Moreover, the fact that members of

\footnotetext{
${ }^{3}$ The randomization was between the formal and the moral ranking, while the traditional ranking was always conducted second. This choice was motivated by the desire to separate the moral and formal rankings, one of which would be implemented in the following stage of the experiment.

${ }^{4}$ Issues of statistical power forced me to leave out the traditional authority ranking from the draw and focus on the dimensions of authority which I expected to be more salient in the study area.
} 
the top and middle group had to be nominated by other session participants increases the likelihood that more vocal individuals took control of the process and suggested their friends as representatives. The empirical analysis will present evidence on the presence of these biases and their effect on leaders and followers' choices.

\subsubsection{Network mapping}

After the ranking exercise, the experiment assistants conducted a mapping of the social network. Subjects were interviewed individually about their relationship with each of the other session participants. For each possible pair $(i, j)$ of participants to a session, therefore, we know whether individual $i$ was a relative, friend, acquaintance or stranger to individual $j$. The social network data will be used in the empirical analysis to explore the correlation existing between individuals' status and the number and status of their social links.

\subsubsection{Contribution decision}

Participants to the experiment were asked to take the following basic decision: "Out of an endowment of 20,000 Pesos, how much to you wish to donate to a biodiversity conservation project?" Participants would keep the difference between contribution and endowment. 20,000 Pesos is equal to 10 USD, about one and a half times the daily farm laborer's wage. This basic decision was taken a total of 13 times by each participant under different conditions, as explained below. To ensure that all 13 decisions of the session were taken seriously, the experimenter made clear to participants that each of them had the same chance of being paid. A random draw at the end of the session decided which choice was implemented.

Participants' contributions financed the establishment of a tree nursery in a primary school. A random draw at the end of the study determined which of the schools serving the sample villages received the funds. Tree nurseries help biodiversity conservation in different ways. First, native trees grown there are used to reforest endangered ecosystems, such as canal banks, where they prevent soil erosion. Second, these ecosystems used to be habitats for endangered animal species, which left following deforestation. Restoring them would bring back native fauna in the area. Third, schools use tree nursery to teach environmental education to kids. Children learn about native species and how they can help preserve the soil and limit the use of chemicals. Finally, everyone in the community can plant trees from the nursery on their own land.

As mentioned above, the decision stage involved a total of 13 choices, divided across a private decision and 4 decision rounds. Participants first took the basic decision in private. The 4 decision rounds consisted of 3 choices each. Each choice was still taken individually, but participants were assigned a partner and received information about the partner's ranking, i.e. the color of the group she belonged to. This information was given through a colored square - orange, blue or brown - drawn on participants' decision sheets. Pairs changed each round, and nobody had the same partner twice. Table 1 summarizes the structure of the decision stage.

[Insert Table 1 here] 
The experimental design varied exogenously pair composition on the basis of participants' ranking. In round 1 , one possible group combination was randomly drawn to be implemented. In round 2 , couples changed by drawing a second combination. In round 3 pairs were formed according to the combination still left to implement. Finally, in round 4 the color combination of round 1 was repeated with different partners. The pair formation process can be illustrated through an example, which is reproduced in Figure 1. In round 1 each member of the Orange group was paired with one member of the Blue group, while members of the Brown group were paired among themselves; in round 2 members of the Orange group were paired with members of the Brown group, while participants in the Blue group were paired among themselves; in round 3, members of the Blue and Brown groups were paired to each other, and members of the Orange group were matched among themselves; finally, in round 4 , the round 1 combination was repeated. The random draws in round 1 and 2 determined the sequence of group combinations implemented.

\section{[Insert Figure 1 here]}

The design introduced a second variation. Within each round, decisions differed in terms of their observability and of the information available on partner's preferences at the time of choosing, as summarized in Table 2. When taking the first decision of the round, participants knew only their partner's ranking, which appeared as a colored square on their decision sheets. They also knew that their choice would be shown to their partner and that, in turn, they would observe their partner's contribution. Before taking the second decision, each participant was shown her partner's contribution in the first decision. Then the experimenter asked everyone to write again their contribution choice on the decision sheet, reminding them that they were free to choose any contribution amount and that the second decision would also be observed by their partners. Finally, before taking the third decision, each participant was shown her partner's contribution in the second decision and asked to make her choice a third time. The third decision differed in that participants knew that it would not be observed by their partner. Throughout the round, the experimenter reminded participants that they were free to contribute whatever they wished, regardless of their previous choices. This process was repeated from the first to the fourth round, for a total of 12 decisions.

[Insert Table 2 here]

\section{Hypotheses}

This section discusses the main hypotheses that will be tested in the empirical analysis, and cites existing theoretical and empirical research in support of each hypothesis. The first question that this study aims to address is how the presence of a leader affects average contribution by a group. Total contribution by a pair may be higher, when at least one leader is part of it, because leaders contribute on average more, because lower-ranked participants make on average higher donations when paired with a leader, or because of a 
combination of these two effects. We, therefore, have to make predictions concerning both leaders and lower-ranked participants' behavior. We expect that leaders will contribute higher amounts to the local public good. This prediction is based on the fact that both the formal and the moral rankings define leadership in relation to individual concerns for the common good, thus leading to the selection of individuals who are likely to have higher valuations of projects benefiting the community. Moreover, empirical evidence from laboratory studies on leadership, which find a positive relationship between individuals' relative status and contributions to a common project (Kumru \& Vesterlund, 2010), suggests that individuals will contribute more when paired with lower-ranked partners than otherwise, and vice versa. This evidence is interpreted as indication that higher-ranked individuals are aware of their responsibility and influence as role models. Overall, these two mechanisms are expected to have a positive effect on leaders' contributions, and through them on total contribution levels by a pair when leaders are among its members. However, such positive effect of leadership may be attenuated by the negative effect of relative status on giving by leaders' partners. The question of which effect will prevail is ultimately an empirical one, that will be addressed in the next section. Predictions on contributions by participants when matched with leaders can also be made on the basis of signaling theories of altruism (Glazer \& Konrad, 1996; Harbaugh, 1998). These models claim that individuals are more altruistic when observed by others, the more so the more they wish to acquire approval from the observers. Based on this perspective, we expect lower-ranked participants to donate more when paired with leaders. Existing empirical evidence lead us to anticipate that the positive effects of leadership will dominate the negative ones, thus leading to an overall increase in pair composition thanks to the presence of a leader.

HYPOTHESIS 1. Pair contribution is higher when leaders are members of a pair.

A second question relating to aggregate contributions to the public good, addressed by this study, concerns which dimension of authority is associated with greater effectiveness of leaders. Theoretical and empirical studies of motivation crowding, and psychological studies of social comparison support the hypothesis that giving will be increased on average by making moral leadership salient. The notion of motivation crowding refers to those settings in which individual behavior is driven by social norms or preferences, or feelings of moral duty. In such contexts, the introduction of external regulations or incentives can change people's perception of the behavior. Voluntary goodwill is turned into a market-like interaction, resulting in fewer people willing to act altruistically (Frey et al., 1996; Frey and Götte, 1999). In the field of natural resource management, research on motivation crowding finds that the exogenous introduction of regulations, monetary sanctions and authorities weakens individuals' intrinsic motivation to contribute to local public goods (Ostrom, 2006; Vatn, 2006). Since contributing to support local biodiversity is not required by any formal law in the study setting, this type of decision has a predominantly moral dimension. According to the motivation crowding literature, therefore, we expect that participants will on average contribute more under the moral than under the formal ranking. Studies on leadership in social psychology support this claim, by 
showing that the relevance of leaders' qualities to the decision under consideration increases leaders' legitimacy. We thus predict that moral leaders will be more salient and legitimate sources of authority than formal leaders in the context of the experiment, and prompt higher contributions by lower-ranked participants.

HYPOTHESIS 2. Moral authority is more effective, i.e. individuals contribute more when moral authority is salient within the experiment.

Finally, this study asks how the presence of a leader within a group influences the evolution of contributions to the public good. An established result in the experimental literature on public good games is that, in the absence of communication or institutions, cooperation tends to unravel over time (Isaac, et al., 1985). This is due to the fact that most individuals are 'conditional cooperators', i.e. they contribute to the public good as long as others do, but withdraw their cooperation as soon as they observe others defecting (Croson, 1999; Fischbacher, et al., 2001). The evidence on complementarities across agents in charitable donations, mentioned in Section 2, supports the claim that individuals tend to conform to others' actions. A number of mechanisms discussed in the literature on social preferences and learning can account for this empirical regularity. Theories of fairness and inequity aversion predict that individuals conform to others' choices in order to minimize payoff inequality (Fehr \& Schmidt, 1999; Bolton \& Ockenfels, 2000). According to fairness models, positive or negative examples by others trigger contribution change by conditionally cooperative individuals (Rabin, 1993; Charness \& Rabin, 2002; Levine, 1998). Theories of conformism and social norms argue that individuals conform to others' actions because deviating from standards of behavior generates disutility in terms of loss of status or painful emotions (Clark \& Oswald, 1998; Lopez-Perez, 2008). Conformism is also endogenously generated by models of social preferences that introduce envy or disutility from deviating from group average behavior in individuals' utility functions (Bernheim, 1994; Maccheroni, et al., 2010). If social status or prestige can be gained through contributions to a public good, for instance because giving is perceived as a signal of wealth or altruism, signaling models also predict that agents adjust their choices to guarantee themselves status at the minimum cost, given others' actions (Benabou \& Tirole, 2006; Glazer \& Konrad, 1996; Ellingsen \& Johannesson, 2008; Harbaugh, 1998). Beside social preference theories, models of social learning claim that others' actions influence individual behavior because they convey information on the value of the public good (Conlisk, 1980; Banerjee, 1992; Bikhchandani, et al., 1992). Although the goal of this paper is not that of testing alternative theories, in Section 7 I will argue that some of these theoretical perspectives appear better suited than others to interpret the empirical findings. Here it suffices to say that all these models, together with the empirical evidence on conditional cooperation, lead us to expect to observe a general tendency by individuals to conform to each other's choices.

The likelihood that participants revise their contribution level upon observing others' decisions will depend on their absolute and relative ranking. We base this prediction on psychological theories of upward 
social comparison. These studies claim that, in determining the appropriateness of their own behavior, individuals compare themselves to others who are believed to possess more knowledge, or fare better, along dimensions relevant to the decision under consideration (Suls, et al., 2002). The tendency to conform to experts and leaders is found to be increasing in their commitment to group goals (Price \& Garland, 1981), attractiveness and relevance within the decision setting (Festinger, 1954). Based on this literature, we anticipate that individuals' tendency to conform to others' choices will be decreasing in their absolute and relative status. This prediction is also supported by laboratory experiments in economics, showing that firstmoving leaders who have higher status or are more cooperative themselves induce higher contributions among followers, and that high status followers are less likely to conform to low status first-movers (Kumru \& Vesterlund, 2010; Gächter, et al., 2011). These arguments are behind the third hypothesis that will be tested in the next section.

HYPOTHESIS 3. Pair contribution is more stable over time when leaders are members of a pair.

\section{Empirical strategy and results}

The empirical analysis in this section follows a series of steps. First, a descriptive investigation of participants' characteristics and of individual traits correlated with altruism and status is conducted (Section 5.1). Then the main findings are presented (Section 5.2): giving is higher when leaders are part of pair, primarily because leaders give more; this effect is stronger when moral authority is made salient within the experiment; and giving decreases less over time when leaders are part of a pair, because leaders only weakly adjust contribution downwards after observing other give less.

\subsection{Demographic and socioeconomic correlates of status and giving}

Table 3 shows participants' average characteristics. Their age and education attainments are in line with country averages. Almost $40 \%$ of them are women. Participants' average age and gender are consistent with the goal of the sampling process of recruiting the head or spouse within each household. The fact that only $10 \%$ of participants had no formal education minimizes concerns that they might not be able to understand the experiment. The majority of participants are smallholder farmers, while only $10 \%$ of them own livestock. Almost $80 \%$ of them reports having suffered income losses due to environmental shocks over the previous year, mostly flooding, droughts and water contamination. The large share of people who depend on farming for their livelihood and who were negatively hit by environmental shocks suggests that participants were likely to value the biodiversity conservation project, as reforestation of canal banks with native species greatly reduces the incidence of floods. This claim is supported by further survey evidence, showing that $94 \%$ of participants believe that the tree nursery project will be useful to their family. Mean farm size is above 2 hectares, and average earnings over the previous week are equal to 35,146 Pesos (17.5 USD). The experiment, therefore, endowed participants with a significant amount of money. Data on the number of associations in which each participant held leadership roles, such as president, secretary, treasures, was also 
collected: this figure ranges from a minimum of 0 to a maximum of 3 associations with a mean of .33 . Each person has an average of 3.65 friends or relatives also attending the session. The share of participants who are ASPROCIG members (57\%) is above that of ASPROCIG members in the study region, a likely consequence of the association's role in the recruitment process.

[Insert Table 3 here]

Participants ranked themselves according to three different criteria, as described in Section 3.2.1. The goal of the formal, moral and traditional authority rankings was to isolate corresponding dimensions of authority. During the discussion, conducted at the end of the exercise, participants listed the main qualities of topranked individuals for each ranking. A qualitative assessment of the results from the discussion shows that the three rankings indeed captured different leadership profiles: individuals at the top of the formal authority ranking are active in the life of the community, contribute to solving its problems and have good links with municipal authorities; those at the top of the moral authority one are good speakers, diplomatic, morally sound, honest and in good relationships with fellow community members; finally, top-ranked individuals in the traditional authority classification are joyful, funny, talented, charismatic and full of enthusiasm. ${ }^{5}$

The three rankings are correlated but not collinear. 50\% of top-ranked individuals in the formal ranking are also in the top group in the moral ranking. As shown in Table 4, pairwise correlation between the formal and moral ranking is $34.9 \%$, between the formal and traditional ranking is $13 \%$, and between the moral and traditional ranking is $-14.2 \%$. All correlations are significant at the $10 \%$ level. This preliminary overview is reassuring of the ability of the three rankings to distinguish between different leadership profiles.

\section{[Insert Table 4 here]}

Individual characteristics correlated with the different rankings are explored next. Table 5 shows results from the following ordered logit regression:

$\operatorname{Prob}\left(\right.$ AbsStatus $\left._{i s}\right)=\beta_{1}+\beta_{2} X_{i s}+\beta_{3}$ Sess $_{s}+\varepsilon_{i s}$

where AbsStatus is $_{\text {is }} 3$ if $i$ is in the top group, 2 if she's in the middle group and 1 if she's in the bottom group, $\operatorname{Sess}_{S}$ are session fixed-effects, and $X_{i s}$ is a vector of individual characteristics: age, gender, marital status, household dependency ratio, a dummy equal to 1 if no kids under 12 live in $i$ 's household, education, per capita household income over the previous week, number of community associations in which $i$ holds leadership roles, number of participants to the session who say that $i$ is a friend or relative, and a dummy equal to 1 if $i$ is an ASPROCIG member. The regression is run for the formal, moral and traditional rankings in Columns 1, 2 and 3 respectively. Column 4 presents results using average rank as dependent variable.

\footnotetext{
${ }^{5}$ Table A1 reports, for each ranking, the top five qualities of top group members mentioned.
} 
Age and education are positively correlated with status in the formal and moral rankings. Holding leadership roles in associations increases the probability of being highly ranked in terms of formal authority. The coefficient on being a woman is negative throughout, and significant for moral and average ranking. Having friends or relatives among session participants increases the likelihood of occupying a high position in the formal and moral ranking. Status in traditional ranking shows a positive and significant correlation only with the number of leadership roles one holds, probably due to the fact that public officers are often required to speak to community members. Overall, regression results are consistent with the purpose of the different rankings. Being educated and occupying positions in community organizations is more relevant for formal authority, while age matters more for moral authority. The fact that almost no proxy of socioeconomic status is significantly correlated with traditional authority is hardly surprising. The qualitative assessment conducted above shows that traditional authority is associated with being funny and enthusiast, qualities for which observable proxies are hard to find. Age, gender, education, roles in community associations and ASPROCIG membership are significant correlates of average ranking.

[Insert Table 5 here]

Now I explore which characteristics are correlated with giving in the experiment. Table 6 shows results from the following regression:

$C_{i s}=\beta_{1}+\beta_{2} X_{i s}+\beta_{3}$ Sess $_{s}+\varepsilon_{i s}$

where $X_{i s}$ is the same vector of individual variables used above. The dependent variable $C_{i s}$ is contribution in the private decision in Column 1 and average contribution over rounds 1 to 4 in Column 2. Results are presented from OLS models for consistency with the specification adopted in the remaining of the section (see footnote 6 below).

ASPROCIG members contribute significantly more throughout the session. This result is consistent with ASPROCIG's mission of pursuing income growth through the protection and enhancement of traditional crops and farming techniques. ASPROCIG considers biodiversity conservation as a necessary condition for development, not as a constraint, and was therefore in favor of the establishment of tree nurseries in the area. The ratio between the number of kids and the number of adults living in a household affects contribution negatively, probably through its impact on household needs. However, having no kids is negatively correlated with giving, both in private and on average, though only the correlation with private donations is significant. This result may reflect the nature of the biodiversity project, which directly benefits kids. Having children may also increase people's concern for the future in general, and environmental sustainability in particular (Dupont, 2004).

[Insert Table 6 here] 
Note that the coefficients on household income are positive but insignificant throughout, probably because of the homogeneity in income levels among participants. The lack of significance of income may be also due to noisiness of the proxy used, i.e. income over the week prior to the experiment. A first evidence against this statement comes from the observation that the household income variable is positively and significantly correlated with respondents' assessments of their own subjective economic status. Moreover, replacing the income variable with asset measures, such as size of land owned, does not change the results. Here and in the rest of the analysis, regressions control for household income per capita and not for farm size, because the use of the latter variable, while not affecting the results, leads to dropping observations for those participants who did not own land or could not estimate precisely the size of their plots.

\subsection{Main results}

This subsection presents the main results from the experiment. It first analyzes aggregate giving and finds that it is a function of status and type of authority made salient within the experiment. It then explores the evolution of giving over time, again showing that contribution revisions differ between leaders and lowerranked participants. These findings are consistent with the predictions derived from the literature in Section 4.

RESULT 1. Pair contribution is higher when leaders are members of a pair. This is due to differences in average contribution levels depending on individual absolute and relative status.

Total contribution by a pair is equal on average to 14,328 Pesos when at least one member of the pair is a leader, and to 12,713 Pesos otherwise. The presence of a leader in a pair, therefore, increases total pair contribution by $13 \%$ relative to the total amount contributed by pairs where both members are lowerranked. This difference is statistically significant, as shown in Table 7, which present results from the following regression:

$C_{p s t}=\beta_{1}+\beta_{2}$ LeaderPair $_{p s t}+\beta_{3}$ Sess $_{s}+\varepsilon_{p s t}$

where $C_{p s t}$ denotes pair $p$ 's total contribution at time $t$ in session $s$ (i.e. the sum of $i$ and $j$ 's contribution, where $i$ and $j$ are the members of pair $p$ ), and LeaderPair $p$ st is equal to 1 if pair $p$ features at least one leader at time $t$. The regression includes session fixed-effects and uses a linear random-effects model (Table 7). ${ }^{6}$

\footnotetext{
${ }^{6}$ In the analysis, I assume the following structure for the error term $\varepsilon_{k s t}: \varepsilon_{i s t}=\mu_{k}+\gamma_{s}+\vartheta_{k s t}$, where $k=i, p$ depending on whether the outcome variable is at the individual or pair level respectively. The first term models the correlation existing between different choices by the same individual (pair). The second term captures the correlation between choices of different individuals (pairs) participating to the same session, generated by observable and unobservable factors varying across sessions. The third term reflects idiosyncratic variations in the error term. In order to control for these different sources of heteroskedasticity, in what follows I will adopt two main empirical models. When the regressors of interest are invariant at the individual level (pair), for instance absolute ranking and type of
} 
[Insert Table 7 here]

The sum of pair members' contributions is significantly higher when at least one of them is a leader. This difference is due to the fact that leaders contribute on average significantly more than lower-ranked participants. Table 8 confirms this claim, showing results from the following regression:

$C_{i s t}=\beta_{1}+\beta_{2}$ Leader $_{i s}+\beta_{3} X_{i s}+\beta_{4}$ Sess $_{S}+\varepsilon_{i s t}$

where $C_{i s t}$ denotes the contribution of individual $i$, taking part in session $s$, at time $t$, and Leader $_{i s}$ is equal to 1 if $i$ is in the top group. The regression in Column 1 features $i$ 's leadership status as the only regressor, while the one in Column 2 adds the following individual controls $X_{i s}$ : age, gender, education, number of community associations in which $i$ holds leadership roles, number of participants to the session who say that $i$ is a friend or relative, and ASPROCIG membership. Comparing the results in Columns 1 and 2, we observe that the difference in leaders' contribution is mainly due to different observable characteristics of leaders and lower-ranked participants: in fact, the inclusion of individual controls reduces the size of the coefficient on leadership by about $30 \%$ and affects its significance level. This finding confirms once again the claim that individuals' positions in the ranking reflect important characteristics within the decision environment under consideration, and suggests that differences in contribution levels cannot be simply induced by placing individuals in leadership positions, regardless of their qualities.

\section{[Insert Table 8 here]}

Unobservable characteristics of leaders may also contribute to determine their higher contributions relative to non-leaders. In particular, leaders may have a higher valuation of environmental conservation. The qualitative data derived from participants' discussion of leaders' characteristics support the idea that topranked individuals, being more committed than others to solving community problems, may also be more willing to promote the conservation of common natural resources. Moreover, survey data show that leaders are significantly more likely than non-leaders to have engaged in conservation activities over the year prior to the experiment, and that $92 \%$ of participants believe leaders to be the most knowledgeable people in the community about environmental issues.

ranking made salient within a session, I will adopt a random-effects model, control for observable and unobservable factors at the session level using session fixed-effect, and cluster the standard errors at the individual level. When the regressions control for time-varying characteristics at the individual level, for instance relative ranking and partner's status, then they will include individual fixed-effects and feature robust standard errors. In order to exploit the advantages in terms of efficiency and control allowed by these model specifications, in the remaining of the session I show results exclusively from linear regressions. The results are robust to the use of alternative specifications, in particular Tobit (contributions are censored at 0 and 20,000 Pesos) and Probit (revision probabilities) models with session fixed-effects and observations clustered at the individual level. The regressions do not include round fixedeffects, unless explicitly stated, because they are never significant. 
While absolute status per se is not associated with significantly higher contributions, previous evidence on leadership suggest that there may be a positive correlation between relative ranking and giving. Laboratory studies on social status show that individuals contribute more to public goods when their followers are of lower standing than when they are matched with same-status partners (Kumru \& Vesterlund, 2010). This finding is interpreted as a proof that higher-ranked individuals are aware of being role models for lower-ranked peers, more so than for same-status ones. In order to test this claim in the setting of the present study, I examine participants' contribution depending on their status relative to that of their partner. Results from the following regression offer clean evidence on the positive relationship between relative status and giving:

$C_{i s t}=\beta_{1}+\beta_{2}$ HigherRank $_{i s t}+\beta_{3} I D_{i s}+\varepsilon_{i s t}$

where HigherRank $k_{i s t}$ is equal to 1 if $i$ is paired with a lower-ranked partner at time $t$ in session $s$. The regression includes individual fixed-effects $\left(I D_{i s}\right)$. Table 9 presents regression results. The positive and significant coefficients on the higher relative status dummy indicates that the same individual contributes significantly more when she is the higher-ranked member of a pair than otherwise.

[Insert Table 9 here]

In order to test whether the effect of relative status is stronger for leaders, I interact the relative ranking dummy with variables equal to 1 if individual $i$ is in the top or middle group respectively:

$$
\begin{aligned}
C_{i s t}= & \beta_{1}+\beta_{2} \text { HigherRank }_{\text {ist }}+\beta_{3} \text { Leader }_{i s}+\beta_{4} \text { Middle }_{\text {is }}+\beta_{5} \text { HigherRank }_{\text {ist }} * \text { Leader }_{\text {is }} \\
& +\beta_{6} \text { HigherRank }_{\text {ist }} * \text { Middle }_{i s}+\beta_{7} X_{i s}+\beta_{8} \text { Sess }_{S}+\varepsilon_{i s t}
\end{aligned}
$$

Individual controls replace individual fixed-effects in this regression, as we wish to investigate the effect of (time invariant) absolute status. Regression results, reported in Table 10, show that both leaders and middleranked participants give more than bottom group members (omitted category). In addition, they confirm that higher relative ranking is associated with higher donations. The sum of the coefficients on the leader and higher-rank dummies, and on their interaction term, is significantly different from $0(p=.060)$, while the corresponding sum of coefficients for middle-ranked participants is not $(\mathrm{p}=.274)$. However, the former sum of coefficients is not significantly different from the latter $(\mathrm{p}=.296)$, suggesting that the effect of relative status on giving is not significantly stronger among leaders than among middle-ranked participants.

[Insert Table 10 here] 
The findings presented in Tables 9 and 10 support previous laboratory evidence on individuals' awareness of being role models for their lower-ranked peers, which we find to be equally strong among leaders and middle-ranked participants. This mechanism combines with leaders' higher valuation of the conservation project in determining the difference in contribution levels between leaders and other participants.

On the contrary, contributions by lower-ranked individuals do not significantly vary depending on whether they are paired with a leader or not. Table 11 reports results from the following regression, which support this claim:

$$
\begin{aligned}
C_{i s t}= & \beta_{1}+\beta_{2} \text { NotLeader }_{i s}+\beta_{3} \text { PartnerLeader }_{i s t}+\beta_{4} \text { NotLeader }_{i s} * \text { PartnerLeader }_{\text {ist }} \\
& +\beta_{5} X_{i s}+\beta_{6} \text { Sess }_{S}+\varepsilon_{i s t}
\end{aligned}
$$

NotLeader $_{\text {is }}$ is equal to 1 if $i$ is in the middle or bottom group, and PartnerLeader ist $_{\text {is }}$ equal to 1 if $i$ 's partner at time $t$ is a leader. Individual controls $X_{i s}$ are included in the regression only in Column 2. The negative coefficients on the two main effects confirm findings from previous regressions, i.e. that giving is decreasing in absolute and relative status. Participants give more when paired with a leader, but this effect is not significant. The desire to impress leaders by donating high amounts does not appear to significantly motivate lower-ranked participants contribution choices.

\section{[Insert Table 11 here]}

To summarize, the first main finding reported in this section is that the presence of a leader in a pair increases total pair contribution. This effect is driven by the fact that leaders give more than non-leaders, especially if their partners are lower-ranked. Two mechanisms combine to produce this result: first, leaders value environmental conservation more than non-leaders; second, there is a general tendency of individuals to increase giving when paired with lower-ranked partners. On the contrary, non-leaders do not make significantly higher contributions when paired with a leader. These results are consistent with previous findings from the experimental literature on leadership and with predictions of social comparison models, while they do not suggest the presence of signaling motives behind participants' choices.

RESULT 2. Moral authority is more effective, i.e. mean contribution is higher when the moral ranking is salient. In particular, leaders and bottom group members contribute significantly more when moral authority is salient.

Next, I examine whether aggregate contribution differs depending on the type of authority made salient within a session. Recall that participants ranked themselves across three different dimensions of authority - formal, moral and traditional - and that one between the formal and the moral ranking was drawn in each session to be implemented. Therefore, each ranking was made salient in half of the sessions and it is possible to compare contribution levels across sessions, depending on which ranking was implemented. 
Average pair contribution is higher when moral ranking is salient. The results from the following regression demonstrate this claim:

$C_{p s t}=\beta_{1}+\beta_{2}$ MoralRank $_{p s}+\beta_{3}$ Sess $_{s}+\varepsilon_{p s t}$

MoralRank $_{p s}$ is equal to 1 if moral authority was made salient for pair $p$ in session $s$. Regression results are presented in Table 12, where the dependent variable is total pair contribution at time $t$ and the regression model is GLS estimation of random-effects model with standard errors clustered at the individual level. Total giving by a pair is on average 2,400 Pesos higher when the implemented group classification is based on the moral authority ranking.

[Insert Table 12 here]

This increase masks differences in behavior across status groups depending on ranking applied. Figure 2 shows average contribution by group, when the moral ranking is salient (dark grey columns) and when the formal ranking is salient (light grey columns). Both leaders and bottom group members give significantly more under the moral than the formal ranking ( $\mathrm{p}$-values of the two-sided t-tests are $\mathrm{p}=.004 \mathrm{and} \mathrm{p}=.002$ respectively). Middle group members, on the contrary, contribute more on average when the formal ranking is salient $(\mathrm{p}=.073)$.

[Insert Figure 2 here]

Insights from theories of motivation crowding and social comparison theories shed some light on these contribution patterns. The arguments that follow are based on the observation that in the study setting the decision to conserve local biodiversity is a voluntary expression of civic engagement and valuation of the environment. Indeed, no formal laws exist to sanction or reward natural resource use, and decisions to preserve the environment fall in the realm of ethical rather than legal norms. As discussed in Section 4, the literature on motivation crowding supports the prediction that individual motivation to contribute will be crowded-in by making the moral dimension of the decision salient, and crowded-out by stressing the role of formal authorities. This prediction applies to all status groups. In addition, theories of social comparison offer a second reason for lower-ranked individuals to contribute more under the moral than the formal authority: if moral leadership is based on attributes perceived to be more salient to the decision under consideration than formal leadership, then lower-ranked individuals will be more inclined to match contributions by moral than by formal leaders. Indeed, a significantly higher share of participants believe leaders to be experts of environmental issues when moral leadership is salient (95\%) than when formal leadership is salient ( $89 \%)$, and this difference is statistically significant ( $\mathrm{p}=.081)$. The combination of these 
two explanations can account for the behavior of leaders and bottom group members, but is inconsistent with that of middle group members.

A tentative explanation for the fact that middle-ranked individuals contribute on average less under the moral than the formal ranking relies on insights from psychological theories of counterfactual thinking. These theories argue that social comparison processes depend not only on the existing social ranking, but also on the most salient counterfactual for the individual in a specific situation (Medvec et al., 1995). According to this literature, people's emotional responses to events are influenced by their thoughts about 'what might have been'. Through an analysis of emotional responses of bronze and silver medalists at the Olympics, Medvec et al. (1995) find that bronze medalists tend to be happier than silver medalists. They attribute this result to the fact that the most salient counterfactual for silver medalists is winning the gold, while for bronze medalists is winning no medals. In the context of this study, if the moral dimension is the most relevant to participants' decisions, the loss of status felt by middle group members relative to leaders could be stronger under the moral than formal ranking. In other words, middle-ranked participants may perceive their own status as 'lower than leaders' status' more strongly under the moral than under the formal ranking. If this were the case, the relationship between relative ranking and giving, established above, would account for the difference in average contribution by middle-ranked participants depending on the type of authority implemented.

To summarize, the second main finding of this study is that average giving is higher when moral leadership is salient. In particular, leaders and bottom group members contribute significantly higher amounts when the moral ranking is made salient. Theories of motivation crowding and social comparison account for these results, given the predominantly moral dimension of the experimental decision.

RESULT 3. Pair contribution is more stable over time when leaders are members of a pair. This is due to different tendencies to conform to others' observed choices depending on individual absolute and relative status.

The first two results presented in this section have focused on aggregate levels of contribution. In particular, Result 1 showed that contribution levels are on average higher when pairs feature at least one leader. Examining the evolution of giving over time, we observe that contribution levels are also more stable when leaders are members of a pair. The following regressions explore contribution trends depending on pair composition:

$$
\begin{aligned}
C_{p s t}= & \beta_{1}+\beta_{2} \text { LeaderPair }_{p s t}+\beta_{3} \text { Decision }_{t}+\beta_{4} \text { LeaderPair }_{p s t} * \text { Decision }_{t}+\beta_{5} \text { Sess }_{s}+\varepsilon_{p s t} \\
C_{p s t}= & \beta_{1}+\beta_{2} \text { LeaderPair }_{p s t}+\beta_{3} \text { Decision }_{t}+\beta_{4} \text { LeaderPair }_{p s t} * \text { Decision }_{t} \\
& +\beta_{5} \text { Sess }_{s}+\beta_{6} \text { Round }_{t}+\varepsilon_{p s t}
\end{aligned}
$$

where LeaderPair ${ }_{\text {pst }}$ was defined above and Decision $_{t}$ denotes the order of decision over time. Regression (9) examines the evolution of total pair contribution over the entire course of a session, while regression (10), 
through the inclusion of round fixed-effects $\left(\right.$ Round $\left._{t}\right)$, focuses on contribution trends within each round. Regression results are presented in Table 13.

[Insert Table 13 here]

The negative coefficients on the time variable indicates that there is a decreasing trend in contribution over time, which is significant within rounds. This result confirms a robust finding in laboratory and field experiments on public good contributions: cooperation starts at positive levels, but deteriorates over time. The presence of leaders in a pair offsets such downward trend: the interaction term LeaderPair pst $^{*}$ Decision $_{t}$ is positive and significant, and the sum of the coefficients on the main effects and interaction terms is not significantly different from zero in both regressions ( $\mathrm{p}=.179$ and $\mathrm{p}=.520$ respectively).

The general downward trend observed among pairs of non-leaders is due to the tendency of individuals, on average, to conform to partners decisions. Recall that participants could revise their contribution choices after observing those of their partners. We can therefore observe how participants' revision choices in $t$ depend on the relative size of own and partner's donation in $t-1$, by regressing the direction of contribution change in $t$ relative to $t-1$ on the sign of the difference between own and partner's contribution in $t-1$ :

$Y_{i s t}=\beta_{1}+\beta_{2} I\left(C_{i s t-1}>C_{j s t-1}\right)+\beta_{3} I\left(C_{i s t-1}<C_{j s t-1}\right)+\beta_{4} I D_{i s}+\varepsilon_{i s t}$

where $Y_{i s t}$ is the likelihood of upward revisions in $t$ relative to $t-l\left[Y_{i s t}=I\left(C_{i s t}>C_{i s t-1}\right)\right]$ in Column 1 of Table 14, and of downward revisions $\left.\left[Y_{i s t}=I\left(C_{i s t}<C_{i s t-1}\right)\right]\right]$ in Column 3. $I\left(C_{i s t-1}>C_{j s t-1}\right)$ is equal to 1 if $i$ gave more than partner $j$ in $t-1$, whereas $I\left(C_{i s t-1}<C_{j s t-1}\right)$ is equal to 1 if $i$ gave less than $j$ in $t-1$. Results are shown using a linear probability. All regressions include individual fixed-effects. Regression coefficients show that participants tend to increase giving after negative lag relative contributions $\left(C_{i s t-1}<C_{j s t-1}\right)$, and decrease it after positive ones $\left(C_{i s t-1}>C_{j s t-1}\right)$. This finding is consistent with field evidence on the complementarity between own and others choices in the realm of charitable giving discussed in Sections 2 and 4.

[Insert Table 14 here]

The tendency to conform does not explain, alone, the general downward trend in giving. For it to produce decreasing levels of aggregate giving, the tendency to conform must be stronger when individuals are exposed to lower than to higher contributions than their own. Indeed, we observe that the sign of lag relative contribution influences not only the direction, but also the magnitude of contribution revisions. Figure 3 shows the relationship between the difference between $i$ and $j$ 's donations in $t-1\left(C_{i s t-1}-C_{j s t-1}\right)$ on the xaxis, and the size of contribution revision by $i\left(C_{i s t}-C_{i s t-1}\right)$ on the y-axis. The regression line appears 
flatter for negative than for positive lag relative contributions. In fact, participants on average revise donations by 2,662 Pesos after contributing more than their partners, and by 2,183 Pesos after contributing more. This difference is statistically significant $(\mathrm{p}=001)$, meaning that participants tend to conform more to others' choices if conformity requires decreases in donation. Indeed, the mean amount of contribution change is -173 Pesos, significantly different from 0.

[Insert Figure 3 here]

The different reactions, that leaders and non-leaders have to others' contributions, lie behind the more stable trend in giving by pairs featuring leaders among their members. In particular, leaders are less likely to decrease donations after contributing a lower amount than their partners in $t$ - 1 . This claim is confirmed by the following regressions, examining both $i$ 's likelihood to revise giving, and the amount of revisions by $i$, as a function of $i$ being a leader, of $i$ giving more or less than her partner in $t-1$ and of their interaction. All regressions control for $i$ 's contribution in the private decision, Private $C_{i s}$, for the amount donated by $i$ 's partner in $t-1, C_{j s t-1}$, and for session fixed-effects:

$$
\begin{aligned}
\text { Increase }_{i s t}= & \beta_{1}+\beta_{2} \text { Leader }_{i s}+\beta_{3} I\left(C_{i s t-1}<C_{j s t-1}\right)+\beta_{4} \text { Leader }_{i s} * I\left(C_{i s t-1}<C_{j s t-1}\right) \\
& +\beta_{5} \text { Private }_{i s}+\beta_{6} C_{j s t-1}+\beta_{7} \text { Sess }_{s}+\varepsilon_{i s t} \\
\text { Decrease }_{i s t}= & \beta_{1}+\beta_{2} \text { Leader }_{i s}+\beta_{3} I\left(C_{i s t-1}>C_{j s t-1}\right)+\beta_{4} \text { Leader }_{i s} * I\left(C_{i s t-1}>C_{j s t-1}\right) \\
& +\beta_{5} \text { Private }_{i s}+\beta_{6} C_{j s t-1}+\beta_{7} \text { Sess }_{S}+\varepsilon_{i s t}
\end{aligned}
$$

Regressions (12a) focus on upward revisions following negative lag relative contributions, whereas (12b) on downward revisions following positive ones. Table 15 shows regression results for the amount of upward revisions in Column 1 [ Increase $_{i s t}=C_{i s t}-C_{i s t-1}$ ], for the likelihood of upward revision in Column 2 Increase $\left._{i s t}=I\left(C_{i s t}>C_{i s t-1}\right)\right]$, for the amount of downward revisions in Column 3 [Decrease ist $=$ $\left.A b s\left(C_{i s t}-C_{i s t-1}\right)\right]$, and for the likelihood of downward revision in Column 4 [Decrease $e_{i s t}=I\left(C_{i s t}<\right.$ $\left.C_{i s t-1}\right)$ ],]. Leaders are significantly less likely to decrease giving when they see their partners donating lower amounts, and when they do, they reduce donations by smaller amounts than non-leaders. Leaders do not behave differently from non-leaders when they face partners who donated more than they did in $t-1$.

\section{[Insert Table 15 here]}

Consistent with the analysis conducted on contribution levels, I now investigate whether the observed differences in leaders' revision choices are, at least partially, due to a more general effect of relative status on the tendency to conform. Results from the following regression are presented in Table 16: 


$$
\begin{aligned}
& \text { Increase }_{i s t}=\beta_{1}+\beta_{2} \text { HigherRank }_{\text {ist }}+\beta_{3} I\left(C_{i s t-1}<C_{j s t-1}\right)+\beta_{4} \text { HigherRank }_{i s t} * I\left(C_{i s t-1}<C_{j s t-1}\right) \\
& +\beta_{5} C_{j s t-1}+\beta_{6} I D_{i s}+\varepsilon_{i s t} \\
& \text { Decrease }_{i s t}=\beta_{1}+\beta_{2} \text { HigherRank }_{i s t}+\beta_{3} I\left(C_{i s t-1}>C_{j s t-1}\right)+\beta_{4} \text { HigherRank }_{i s t} * I\left(C_{i s t-1}>C_{j s t-1}\right) \\
& +\beta_{5} C_{j s t-1}+\beta_{6} I D_{i s}+\varepsilon_{i s t}
\end{aligned}
$$

The outcome variables are the same as in the previous table. The regressions focus on the effect of varying relative status on individuals' revision amount (Columns 1 and 3) and likelihood of revision (Columns 2 and 4), by including individual fixed-effects and controlling for a dummy equal to 1 if individual $i$ in session $s$ is the highest-ranked member of a pair at time $t$, HigherRank $_{i s t}$. Relative status is negatively correlated with an individual's tendency to conform, both upwards and downwards. In fact, being the higher-ranked member of a pair is associated with a significantly lower likelihood to revise donation upwards following negative lag relative contributions, and downwards following positive ones. Equivalently, these findings show that individuals are more likely to conform to partners' choices when the latter have higher status. The results on revision amounts go in the same direction, but regression coefficients on the interaction terms are not significant.

[Insert Table 16 here]

In order to test whether the effect of relative status alone is responsible for the observed differences in leaders' downward revision choices, I run t-tests of the likelihood to decrease donations, $I\left(C_{i s t}<C_{i s t-1}\right)$, following positive lag relative contributions, $I\left(C_{i s t-1}>C_{j s t-1}\right)$, when $i$ is ranked higher than her partner, depending on whether $i$ is in the middle or in the top group. Middle-ranked participants revise giving downward $54.5 \%$ of the times in such situations, while the corresponding figure for leaders is only $39.3 \%$. This difference is statistically significant ( $\mathrm{p}=.008)$. On the contrary, no significant differences are observed in upwards revision choices by leaders and middle group members following negative lag relative contributions $(\mathrm{p}=.564)$. Consistent with previous results on donation levels, leaders' behavior appears to be driven by a combination of effects. There exist a general tendency by higher-ranked individuals to conform less to partners' choices, which is in line with predictions of upward social comparison models. In addition, leaders are even less likely than other higher-ranked participants to lower their contribution to match those of their partners', a fact which could be explained by their higher valuation of the conservation project.

We observed that lower-ranked members of a pair are more likely to conform to their partners' choices than their higher-ranked counterparts. In order to test whether further differences in revision choices by lower-ranked participants exist depending on whether their partners are leaders, I show results from the following regressions, which focus exclusively of non-leaders (Table 17):

$$
\begin{aligned}
\text { Increase }_{i s t}= & \beta_{1}+\beta_{2} \text { PartnerLeader }_{i s t}+\beta_{3} I\left(C_{i s t-1}<C_{j s t-1}\right)+\beta_{4} \text { PartnerLeader }_{i s t} * \\
& I\left(C_{i s t-1}<C_{j s t-1}\right)+\beta_{5} C_{j s t-1}+\beta_{6} I D_{i s}+\varepsilon_{i s t}
\end{aligned}
$$




$$
\begin{aligned}
\text { Decrease }_{i s t}= & \beta_{1}+\beta_{2} \text { PartnerLeader }_{i s t}+\beta_{3} I\left(C_{i s t-1}>C_{j s t-1}\right)+\beta_{4} \text { PartnerLeader }_{i s t} * \\
& I\left(C_{i s t-1}>C_{j s t-1}\right)+\beta_{5} C_{j s t-1}+\beta_{6} I D_{i s}+\varepsilon_{i s t}
\end{aligned}
$$

The dependent variables are the same as in the previous tables. As above, regressions control for partner's contribution amount in $t-1$ and individual fixed-effect, and results are derived using linear probability models. After giving less than their partners, participants are more likely to revise their donation upwards if partners are leaders than if they are not, and the amount of contribution increase is also higher in this case. However, neither effect is statistically significant. Similarly, there are no significant differences in downward revision choices depending on partner's leadership status.

\section{[Insert Table 17 here]}

Non-leaders' tendency to conform doesn't significantly differ depending on the type of authority made salient within the experiment. In particular, the likelihood that participants revise their donations upwards, after observing a higher-ranked partner contribute more, is higher when the moral ranking is salient (49\%) than when it is not $(42.5 \%)$, but this difference is not statistically significant $(\mathrm{p}=.232)$.

This final part of the section has demonstrated that the presence of leaders in a pair makes cooperation sustainable through the combination of two mechanisms. Individuals are in general less likely to conform to their partners' choices when they are the higher-ranked members of their pair. Moreover, when paired with partners who donate lower amounts, leaders tend to decrease contributions even less frequently than other higher-ranked participants. The next section checks whether the results presented so far are determined by biases deriving from the ranking procedure used within the experiment.

\section{Robustness checks}

The ranking process that was used to divide participants into groups may have introduced biases in the attribution of status to participants. This section examines two main potential sources of bias. The first concerns the constraint imposed by the procedure, that status groups be equally-sized. The second derives from the relationship between leadership and friendship links among session participants. In what follows, I will provide evidence that demonstrates how the main results of this paper are not a by-product of the ranking procedure used. On the contrary, the classification process may cause an under-estimation of true leadership effects.

By imposing exogenously that one-third of participants belong to the top group, one-third to the middle group and the remaining third to the bottom group, the ranking determined exogenously a discontinuity in ranking. It is likely that a ranking process, which left the size of groups unrestricted, would result in a different number of participants classified as leaders. In order to investigate whether a misalignment between underlying leadership and status within the experiment exists, and what consequences 
it has on the empirical results, I examine the differences in behavior within groups and near the thresholds between status groups.

The analysis of within-group differences in contribution is possible because the experimenter recorded the exact order in which participants were selected into the top two groups. Since the bottom group was defined in a residual way, no within group differences can be defined there. For the top and middle groups, therefore, we can explore whether individuals selected early on into the group behave differently than fellow group members nominated later. A simple distinction is between the first half of participants selected into the group and the remaining members of the same group. Figure 4 shows mean contribution of participants by absolute status, distinguishing between the top and the bottom half of each group. Focusing on the top group, we observe that those selected first as leaders give significantly more than those selected last ( $\mathrm{p}=.013)$. The middle group displays an opposite pattern, i.e. the lower-ranked components of the group contribute on average significantly more than the higher-ranked ones $(\mathrm{p}=.002)$.

[Insert Figure 4 here]

Within group differences in behavior can result from the fact that the qualities related with leadership are stronger among the individuals nominated first, and progressively get diluted as we move down the ranking. Since intrinsic valuation of local public goods is a prominent quality of leaders according to qualitative and survey data, this would explain the fact that 'top leaders' donate more to environmental conservation than all lower-ranked participants. Indeed, once we control for observable characteristics of participants, the differences in giving between top and bottom-ranked members of a group lose significance, as shown by the results of the following regression:

$C_{i s t}=\beta_{1}+\beta_{2}$ TopHalfGroup $i s+\beta_{3} X_{i s}+\beta_{4} \operatorname{Sess}_{s}+\varepsilon_{i s t}$

where TopHalfGroup is is equal to 1 if $i$ is in the top half of her group and 0 otherwise. Column 1 of Table 18 considers top group members only, while Column 2 focuses on members of the middle group. Regression results tells us that within group differences in giving are primarily driven by individual characteristics correlated with ranking order. Although not significant, the negative coefficients on the TopHalf - Group is dummies suggest that giving by lower-ranked members of a group is higher than that by their fellow group members, once their individual characteristics are controlled for. This result is consistent with psychological theories of counterfactual thinking. According to this perspective, for lowest-ranked individuals within a group the most salient counterfactual is represented by members of the lower status group (because they could have easily ended there). Their behavior would therefore be driven by a feeling of being role models for those ranked below, rather than by a feeling of relative deprivation for not having reached higher positions in the ranking. The positive correlation existing between relative ranking and giving, found in the previous section (Result 1), further supports this argument. 
[Insert Table 18 here]

The differences in contribution levels between participants in the lower half of the top group and those in the upper half of the middle group, significant when we run a simple t-test ( $\mathrm{p}=.002)$, also lose significance once we control for individuals characteristics. A similar regression to (15) is run, focusing this time only on participants around the status threshold between top and middle group:

$C_{i s t}=\beta_{1}+\beta_{2}$ TopHalfMiddleGroup $i s+\beta_{3} X_{i s}+\beta_{4}$ Sess $_{s}+\varepsilon_{i s t}$

where TopHalfMiddleGroup ${ }_{i s}$ is equal to 1 if $i$ is in the top half of the middle group and to 0 if $i$ is in the bottom half of the top group. The results, presented in Table 19, show that there is no statistically significant difference in contribution between the lowest-ranked among the leaders and the highest-ranked within the middle group, once we control for individual characteristics. This finding further reassures us of the ability of the ranking to reflect actual differences in individual characteristics.

[Insert Table 19 here]

The presence of within-group differences in giving has relevant implications, especially in terms of leadership effects. If the ranking process led to the inclusion of individuals with progressively weaker leadership profiles into the top group, then the leadership effects observed here are lower bounds of what we would observe, had the selection into the leaders' group been restricted to fewer individuals.

I now turn to examining the second potential source of bias generated by the ranking process. By accepting as candidates in the top two groups only those nominated by fellow session participants, the ranking may have induced the selection of leaders on the basis of friendship networks rather than individual qualities. If this were the case, the fact that leaders do not adjust their contributions to match lower ones by non-leaders, while non-leaders revise giving upwards in order to conform to leaders, could be a consequence of the effect of friendship on influence. This outcome would result if individuals were more inclined to conform to the choices of friends than of strangers, if those, whom leaders consider friends, belonged to their own group, and if, concurrently, lower-ranked participants had more friends in the top group than in other groups. Table 20 shows average number of friends by status group among leaders and non-leaders. Overall, leaders say to have fewer friends also attending the session than non-leaders. This difference is mainly due to the smaller number of friends that leaders declare to have among lower-ranked participants, relative to nonleaders. The difference between leaders and non-leaders in the number of top-ranked friends mentioned is also small and not significant.

[Insert Table 20 here] 
Table 20 shows that leaders do not appear to have significantly fewer friends among non-leaders than lowerranked participants, and that non-leaders have only slightly more friends among leaders than top-ranked participants. This is preliminary evidence against the possibility that experimental results be driven by statusspecific network differences. Still, we wish to check whether differences in friendship relationships can account for the differences we observe in contributions depending on absolute and relative status. If individuals contribute to the conservation project because it can be beneficial to their friends, the more so the needier their friends are, then giving should be increasing in the number of lower-ranked friends. Moreover, if donations are believed to please friends who will benefit from them, then we expect giving to respond to partner's group, depending on the number of friends one has in that group. I test these predictions through the following regressions:

$$
\begin{aligned}
C_{i s t}= & \beta_{1}+\beta_{2} \text { LeaderFriends }_{i s}+\beta_{3} \text { NonLeaderFriends }_{i s}+\beta_{4} X_{i s} \\
& +\beta_{5} \text { PrivateC }_{i s}+\beta_{6} C_{j s t-1}+\beta_{7} \text { Sess }_{s}+\varepsilon_{i s t} \\
C_{i s t}= & \beta_{1}+\beta_{2} \text { LeaderFriends }_{i s}+\beta_{3} \text { PartnerLeader }_{\text {ist }}+\beta_{4} \text { LeaderFriends }_{i s} * \text { PartnerLeader }_{i s t} \\
& +\beta_{5} \text { NonLeaderFriends }_{i s}+\beta_{6} \text { NonLeaderFriends }_{i s} \text { PartnerNonLeader }_{i s t} \\
& +\beta_{7} \text { PrivateC }_{i s}+\beta_{8} C_{j s t-1}+\beta_{9} \text { Ses }_{s}+\varepsilon_{i s t}
\end{aligned}
$$

where (18a) examines how contribution by individual $i$ at time $t$ depends on the number of friends $i$ has among leaders (LeaderFriends $s_{i s}$ ) and non-leaders (NonLeaderFriends $s_{i s}$ ), controlling for contribution in the private decision, partner's donation in $t-1$, individual characteristics (including absolute status) and session fixed-effects. Regression formula (18b) adds to these variables dummies equal to 1 if $i$ 's partner at time $t$ is a leader (PartnerLeader ${ }_{i s t}$ ), and interaction terms between partner's status and number of friends $i$ has in the corresponding status category (LeaderFriends is $_{*}$ PartnerLeader $_{\text {ist }}$ and NonLeaderFriends $s_{\text {is }}$ PartnerNonLeader $_{\text {ist }}$ ). The constant in (18b) captures average contribution when $i$ 's partner is not a leader, and regression coefficients reflect deviations from this baseline contribution level.

Table 21 shows results from (18a) in Column 1 and from (18b) in Column 2. The number of friends among leaders and non-leaders does not appear to significantly affect contributions, nor does the interaction between partner's status and number of friends $i$ has in the corresponding status group. These findings demonstrate that leadership effects are not driven by the influence of friendship networks on status and giving.

[Insert Table 21 here]

Overall, the results presented in this section reassure us of the ability of ranking within the experiment to reflect leadership status within the community, and mitigate concerns that leadership effects observed here 
may be a by-product of the specific ranking procedure used. On the contrary, the ranking process, by assigning leadership status to as many as one-third of participants, may have attenuated its effects.

\section{Mechanisms}

This section reviews the experimental results with the purpose of interpreting them in light of existing theories of social preferences, learning and social comparison. In the course of the analysis, evidence in support or against specific perspectives will be offered. This section is not meant to offer an exhaustive account of all theoretical perspectives that can account for the empirical results presented so far. The goal of this review is simply to focus on specific theoretical frameworks and discuss their consistency with the experimental data.

A common framework used in economics to explain social influence is offered by models of learning (Conlisk, 1980; Banerjee, 1992; Bikhchandani et al., 1992). Under this perspectives, individuals conform because others' choices convey information about the value of alternative outcomes under consideration. The heterogeneity in the tendency to conform that we observe between leaders and non-leaders can be explained by assuming that information conveyed by leaders' choices is more valuable, and thus individuals conform more to the actions of leaders than of lower-ranked peers. If learning were the only mechanism at work, we would observe a decreasing marginal effect of information, reflected in the likelihood that observing others' choices induces individuals to revise their own. Observing a decreasing frequency of revisions over time would, therefore, be evidence of the role of learning within the experiment. The frequency of revisions is $77.8 \%, 77.1 \%, 78.1 \%$ and $79.1 \%$ in the first, second, third and fourth round respectively. Rather than decreasing, the frequency of revisions increases over time, which is evidence against the presence of powerful learning effects within the experiment.

Signaling theories of altruism also predict a positive correlation between own and others' contribution, stronger when the latter are of higher status (Glazer \& Konrad, 1996; Harbaugh, 1998). According to these models, agents' pro-social behavior is motivated by the desire to gain approval from their

peers. Such desire is stronger the more respected their peers are. In the setting of this study, these assumptions imply that low status participants contribute to the public good in order to impress their high status partners. Upon observing their high-ranked counterparts contribute less than they did, and realizing that approval could be bought more cheaply, they reduce their donations. The same framework predicts the low tendency to conform to the choices of lower-ranked partners on the part of leaders. The role of giving as a signal of desirable qualities to others depends on the fact that contribution choices are observable. When they are not, the signaling motive to contribute disappears. In order to test whether this motive is at work within the experiment, individual contributions are compared depending on whether they are observable or not. Table 22 shows results from the following regressions:

$C_{i s t}=\beta_{1}+\beta_{2}$ Observed $_{i s t}+\beta_{3} C_{j s t-1}+\beta_{4} I D_{i s}+\varepsilon_{i s t}$ 


$$
\begin{aligned}
C_{i s t}= & \beta_{1}+\beta_{2} \text { PartnerLeader }_{i s t}+\beta_{3} \text { Observed }_{i s t}+\beta_{4} \text { PartnerLeader }_{\text {ist }} * \text { Observed }_{\text {ist }} \\
& +\beta_{5} C_{j s t-1}+\beta_{6} I D_{i s}+\varepsilon_{i s t}
\end{aligned}
$$

where (19a) regresses $i$ 's contribution at time $t$ on whether the choice was observed, partner's contribution at $t-1$ and individual fixed-effects (Column 1), while (19b) tests whether the effect of observability depends on i's partner being a leader (Column 2). Regression results show that contribution amounts are not significantly higher depending on whether choice is observed or not. The status of the partner also doesn't matter. These findings are inconsistent with the presence of signaling motives behind participants' choices. However, signaling models claim that individuals care about projecting a good image not just to others, but also to themselves (Benabou \& Tirole, 2006). Unfortunately the available data does not allow testing whether selfsignaling motives are relevant within the experiment.

[Insert Table 22 here]

Theories of inequity aversion make predictions consistent with the empirical findings of this study: after observing others' contribution amounts, individuals revise their choices so as to minimize payoff inequality. Moreover, these models assume that agents are more averse to disadvantageous inequality, and thus more likely to reduce giving after learning that their partners earned more, than to increase it after learning that their partners earned less. Although no formal test exists of whether inequity aversion is at work within the experiment, a remark can be made. According to inequity aversion theory, we would expect revisions choices by bottom group members to be correlated with the perceived income of top-ranked individuals: if top group members are believed to be the richest in the community, then by earning more than others through the experiment they would further increase inequality. Inequality would be reduced instead if leaders were believed to be the poorest in the community. In the survey, participants were asked if they thought that top group members were among the richest people in the community. Only $24 \%$ of bottom-ranked participants answered affirmatively to this question. Moreover, the probability that low status participants decrease giving in $t$ after learning that their top-ranked partners gave less than they did in $t-1$, is not correlated with the belief that top-ranked partners are rich.

As for reciprocity models, the asymmetry we observe in revision patterns is consistent with what Charness and Rabin (2002) call 'concern withdrawal': individuals do not display strong positive reciprocity, but are quick to withdraw their concern for other agents' wellbeing when the latter act uncooperatively. This theoretical framework can account for the fact that participants to the experiment tend to revise giving downwards more than upwards, and for the absence of effects of observability.

In order to explain why the tendency to conform to others' actions is negatively correlated with individuals absolute and relative ranking, all theories reviewed so far need to be combined with models of social comparison, which argue that agents look upwards on the status ladder when assessing their own behavior. Survey data confirm that participants' opinions on their own ability to influence others depend on 
status: asked to rate on a scale from 1 to 4 - where 1 is 'very' and 4 is 'not at all'- how much influence they had on community outcomes, leaders and non-leaders' mean answers were on average 1.4 and 1.7 respectively. Such difference is statistically significant ( $\mathrm{p}=.011$ ), even more so if we focus on moral leaders ( $\mathrm{p}=.006$ ), whose answer was 1.3 on average. ${ }^{7}$

The only models that do not require to be complemented by social comparison theories, in order to account for the different behavioral patterns that we observe in the data, are social norms and conformity models. There, the asymmetry between upward and downward revision amounts results from that between honor from complying with the norm and shame from deviating from it. Moreover, the presence of differences in honor and stigma depending on individual status would justify the different revision patters by leaders and non-leaders. Honor from complying could be decreasing in status, thus explaining lower-ranked willingness to revise contributions upwards upon observing higher-ranked partners donate more. On the other hand, the shame from not contributing could be increasing in status, which would explain why leaders fail to conform to lower-ranked partners who contribute lower amounts. The presence of context-dependent social norms has been demonstrated by empirical studies (Krupka \& Weber, 2010), showing how people's opinions on what is appropriate behavior are strongly dependent on the decision environment. Since differences across, and within, groups enter the definition of participants' choice environment in the setting of this study, theories of social norms would predict them to be associated with heterogeneities in individual behavior.

To summarize, among social preference theories, some appear to perform better than others in explaining the main empirical findings of this study. In particular, theories of conformism and social norms, and a combination of reciprocity and social comparison models appear to be capable of explaining the larger set of empirical findings from this study. This is, of course, no conclusive evidence in favor of one perspective over others. On the contrary, different mechanisms may combine to produce observed behavior. Further experiments would be needed to formally test the predictive power of the different theories reviewed in this section.

\section{Conclusions}

Through a novel methodological approach, combining a participatory ranking exercise, which identified different types of existing leaders within the community, and a public-good game, in which participants contributed to an actual biodiversity conservation project, this paper has shown that the presence of leaders is associated with higher and more stable contributions by the group over time. First, leaders give more, and this by itself makes total pair contribution significantly higher when leaders are part of it. Second, top-ranked individuals show a low tendency to conform to (lower) partners' contribution. These results are driven by the

\footnotetext{
${ }^{7}$ While social comparison theories can account for leadership effects in giving and revision choices, they cannot explain the fact that bottom-ranked participants within a group contribute more than top-ranked members of the same group. We noted that theories of counterfactual thinking can explain why participants, who just missed-out being in a lower group, tend to compare themselves primarily to lower-ranked peers and feel the responsibility of being role models for them, much in the same way as leaders feel towards non-leaders. While interesting, this effect is not significant once individual characteristics are controlled for.
} 
combination of leaders' high valuation of the local public good provided through their donations, and of a general positive relationship between relative status and giving, both on average and over time. These effects are enhanced when leadership is defined along a dimension that is relevant for the decision under consideration. The results also show that, beyond the general relationship between relative status and behavior, non-leaders' actions do not significantly vary depending on whether their partners are leaders.

It is an established fact in sociology and economics that innovation processes take off when opinion leaders and highly connected individuals decide to adopt (Rogers, 1962; Katz \& Lazarsfeld, 1955). In practice, identifying these key individuals in unfamiliar settings may be challenging and costly. This study presents a solution to the targeting problems, by demonstrating how a simple ranking exercise can help identify natural leaders within a community. The empirical results presented here suggest that the identity of effective leaders depends on the nature of the decision under consideration. For leaders to feel responsibility as role models, it is therefore crucial that they are selected on the basis of characteristics salient to the specific issue at hand. Once these conditions are fulfilled, this study suggests that interventions targeted to local leaders, for instance environmental education programs, may have a significant impact on the broader community.

The results from this study go against conventional wisdom in development economics. The literature on community driven development warns against the risk of elite capture of development programs and looks at the power of local elites as a negative factor. I show instead that elites can play a positive role. This result may depend on the way leaders are selected within the experiment or on other social and cultural features of the study area. Indeed, the ranking process provided legitimacy to leaders in the context of the experiment. Testing the robustness of the experimental findings to leaders' selection process and characteristics could be an interesting direction for further research.

Generalizability of the results could be interestingly explored along two other dimensions, which would address limitations of this study. First, the positive role played by local leaders in the experiment may depend on specific features of the experimental design. In particular, before deciding how much to contribute, participants discussed the qualities of top group members for each ranking. By spelling out what was expected of them, this discussion may have influenced top group members' behavior. The notion that placing responsibility for the common good in the hands of local elites could have a positive effect on their conduct has great policy relevance and would deserve further empirical testing.

Second, this study shows that social status affects choices when individuals face a decision with a strong normative content. The 'right' choice there depends more on ethical concerns than on objective considerations. Still, the experiment faces participants with a decision whose outcomes are uncertain. Under this respect, the decision environment within the experiment is similar to those confronting farmers when they take information-based choices, such as technology and innovation adoption. An additional direction for further research would explore the role of leadership for behavior transmission in decision contexts with varying ethical and informational contents. 
Besides its limitations and possible extensions, this research is the first to identify the effect of different types of naturally occurring leadership on group cooperation. Field experiments offer a unique opportunity to investigate long-term determinants of the voluntary provision to public goods in a natural environment. This experiment demonstrates that the presence of leaders can lead to improvements in group cooperation, especially if leadership is based on criteria relevant to group decisions and on legitimate selection processes. 


\section{References}

Adams J.S. (1963), Toward an Understanding of Inequity, Journal of Social Psychology, 67, 422-436.

Adams J.S. (1965), Inequity in Social Exchange, in Berkowitz L. (ed.), Advances in Experimental Social Psychology, Academic Press, New York and London.

Alpízar F. and Martinsson P., (2010), Don't Tell Me What to Do, Tell Me Who to Follow! - Field Experiment Evidence on Voluntary Donations, Working Papers in Economics 452, Göteborg University, Department of Economics.

Andreoni J. and Miller J. (2002), Giving According to GARP: An Experimental Test of the Consistency of Preferences for Altruism, Econometrica, 70, 737-753.

Andreoni J. and Petrie R. (2004), Public goods experiments without confidentiality: a glimpse into fundraising, Journal of Public Economics, 88, 1605-1623.

Angrist J. and Pischke J. (2009), Mostly Harmless Econometrics: An Empiricist's Companion, Princeton University Press.

Arbak E. and Villeval M.C. (2007), Endogenous Leadership: Selection and Influence, IZA Discussion Paper No. 2732.

Arce D.G. (2001), Leadership and the aggregation of international collective action, Oxford Economic Papers, 53, 114-137.

Ball S., Eckel C., Grossman P.J. and Zame W. (2001), Status in Markets," Quarterly Journal of Economics, $116,161-188$.

Bandiera O. and Rasul I. (2006), Social Networks and Technology Adoption in Northern Mozambique, Economic Journal, 116, 869-902.

Banerjee A.V. (1992), A Simple Model of Herd Behavior, Quarterly Journal of Economics, 107, 797-817.

Bénabou R. and Tirole J. (2006), Incentives and Prosocial Behavior, American Economic Review, 96, 16521678.

Becker G. (1974), A Theory of Social Interactions, Journal of Political Economy, 82, 1063-1093.

Beekman, G., Bulte E. and Nillesen E. (2011), Corruption, Investments and Contributions to Public Goods: Experimental Evidence from Rural Liberia, Working Paper.

Bernheim D. (1994), A Theory of Conformity, Journal of Political Economy, 102, 841-77.

Besley T. and Case A. (1993), Modeling Technology Adoption in Developing Countries, American Economic Review, 83, 396-402.

Bikhchandani S., Hirshleifer D. and Welch I. (1992), A Theory of Fads, Fashion, Custom, and Cultural Change as Information Cascades, Journal of Political Economy, 100, 992-1026.

Bohnet I. and Frey B. (1999), Social distance and other-regarding behavior in dictator games: comment, American Economic Review, 89, 335-339.

Bracha A., Heffetz O. and Vesterlund L. (2009), Charitable Giving: The effects of Exogenous and Endogenous Status, University of Pittsburgh Working Paper. 
Bolton G. and Ockenfels A. (2000), A Theory of Equity, Reciprocity, and Competition, American Economic Review, 90, 166-193.

Byrne D. (1971), The Attraction Paradigm, New York: Academic Press.

Cameron C., Gelbach J. and Miller D. (2008), Bootstrap-Based Improvements for Inference with Clustered Errors, Review of Economics and Statistics, 90, pp.414-427.

Cameron C and Miller D. (2010), Robust Inference with Clustered Data, Working Paper 10-6, UCDavis.

Cardenas J.C., 2000. How do Groups Solve Local Commons Dilemmas? Lessons from Experimental Economics in the Field. Environment, Development and Sustainability 2, 305-322.

Cardenas J.C., Stranlund J. and Cleve W., 2000. Local Environmental Control and Institutional CrowdingOut. World Development 28, 1719-1733.

Cardenas J.C. (2004), Norms from Outside and from Inside: an Experimental Analysis on the Governance of Local Ecosystems, Forest Policy and Economics, 6, 229-241.

Cardenas J.C. and Ostrom E. (2004), What do people bring into the game? Experiments in the field about cooperation in the commons, Agricultural Systems, 82, 307-326.

Chambers R. (1994), The Origins and Practice of Participatory Rural Appraisal, World Development, 22, 953-969.

Charness G. and Rabin M. (2002), Understanding Social Preferences with Simple Tests, Quarterly Journal of Economics, 117, 817-869.

Chattopadhyay R. and Duflo E. (2004), Women as Policy Makers: Evidence from a Randomized Policy Experiment in India, Econometrica, 72, 1409-1443.

Cialdini R. and Goldstein N. (2004), Social influence: compliance and conformity, Annual Review of Psychology, 55, 591-621.

Clark A. and Oswald A. (1998), Comparison-concave utility and following behaviour in social and economic settings, Journal of Public Economics, 70, 133-155.

Clastres P. (1974), Society Against the State, Zone Books.

Conlisk J. (1980), Costly optimizers versus cheap imitators, Journal of Economic Behavior and Organizations, 1, 275-293.

Croson, R. (1999), Theories of Altruism and Reciprocity: Evidence from Linear Public Goods Games, Discussion Paper, Wharton School, University of Pennsylvania.

Duflo E., Dupas P. and Kremer M. (2008), Peer Effects, Teacher Incentives, and the Impact of Tracking: Evidence from a Randomized Evaluation in Kenya, NBER Working Paper No. w14475.

Dupont D. (2004), Do children matter? An examination of gender differences in environmental valuation, Ecological Economics 49, 273-286.

Ellingsen T. and Johannesson M. (2008), Pride and Prejudice: The Human Side of Incentive Theory, American Economic Review, 98, 990-1008.

Falk A. and Ichino A. (2006), Clean Evidence on Peer Effects, Journal of Labor Economics, 24, 39-58 
Fehr E. and Schmidt K. (1999), A Theory of Fairness, Competition, and Cooperation, Quarterly Journal of Economics, 114, 817-868.

Fehr E. and Schmidt K. (2001), Theories of Fairness and Reciprocity, Discussion Paper in Economics 14, University of Munich, Department of Economics.

Festinger L. (1954), A Theory of Social Comparison Processes, Human Relations, 7, 117-140.

Fischbacher U., Gächter S. and Fehr E. (2001), Are People Conditionally Cooperative? - Evidence from Public Goods Experiments, Economic Letters, 71, 397-404.

Foss N.J. (2001), Leadership, Beliefs and Coordination: an Explorative Discussion, Industrial and Corporate Change, 10, 357-388.

Frank R. H. (1985), Choosing the right pond. Human behavior and the quest for status, Oxford University Press: New York and Oxford.

Frey B. and Meier S. (2004), Social Comparisons and Pro-social Behavior: Testing "Conditional Cooperation" in a Field Experiment, American Economic Review, 94, 1717-1722.

Gaechter S. and Renner E. (2005), Leading by Example in the Presence of Free Rider Incentives, Mimeo, University of Nottingham.

Gaechter S., Nosenzo D., Renner E. and Sefton M. (2009), Who Makes a Good Leader? Social Preferences and Leading-by-Example, Levine's Working Paper Archive.

Gaechter S. and Thoni C. (2011), Peer Effects and Social Preferences in Voluntary Cooperation, Unpublished Manuscript.

Glaeser E., Laibson D., Scheinkman J. and Soutter C. (2000), Measuring Trust, Quarterly Journal of Economics, 115, 811-846.

Glazer A. and Konrad K. (1996), A Signaling Explanation for Charity, American Economic Review, 86, 1019-1028.

Harbaugh W.T. (1998), What do Donations Buy? A Model of Philanthropy Based on Prestige and Warm Glow, Journal of Public Economics, 67, 269-284.

Harrison G.W. and List J.A. (2004). Field Experiments. Journal of Economic Literature, 17, 1009-1055.

Hermalin B. E. (1998), Toward an Economic Theory of Leadership: Leading by Example, American Economic Review, 88, 1188-1206.

Hollander H. (1990), A Social Exchange Approach to Voluntary Cooperation, American Economic Review, 80, 1157-67.

Isaac M., Walker J. and Williams A. (1994), Group Size and the voluntary Provision of Public Goods, Journal of Public Economics, 54, 1-36.

Jones B.F. and Olken B.A. (2005), Do Leaders Matter? National Leadership and Growth Since World War

II, The Quarterly Journal of Economics, 120, 835-864

Katz E. and Lazarsfeld P. (1955), Personal Influence: the Part Played by People in the Flow of Mass Communications, New York: Free Press. 
Komai M., Stegeman M. and Hermalin B. E. (2007), Leadership and Information, American Economic Review, 97, 944-947.

Kosfeld, M. and Rustagi D. (2011), "Leader Punishment and Cooperation in Groups: Experimental Field Evidence from Commons Management in Ethiopia”, Working Paper.

Kremer M. and Levy D. (2008), Peer Effects and Alcohol Use among College Students, The Journal of Economic Perspectives, 22, 189-185.

Kumru C. and Vesterlund L. (2010), The Effects of Status on Voluntary Contribution, Journal of Public Economic Theory, 12, 709-735.

Latané B. (1981), The Psychology of Social Impact, American Psychologist, 36, 343-356.

Lazear E. P. (2010), Leadership: A Personnel Economics Approach, NBER Working Papers 15918.

Levine D. (1998), Modeling Altruism and Spitefulness in Experiments, Review of Economic Dynamics, 1, 593-622.

List J.A. and Lucking-Reiley D. (2002), The Effects of Seed Money and Refunds on Charitable Giving: Experimental Evidence from a University Capital Campaign, Journal of Political Economy, 110, 215233.

Lizzeri A.and Yariv L (2010), Sequential Deliberation, Working paper, Caltech.

Lopéz-Peréz R. (2008), Aversion to Norm-Breaking: a Model, Games and Economic Behavior, 64, pp.237267.

Maccheroni F., Marinacci M. and Rustichini A. (2010), Pride and Diversity in Social Economics, Working Paper, Università Bocconi.

Macours K. and Vakis R. (2009), Changing households'investments and aspirations through social interactions : evidence from a randomized transfer program, Policy Research Working Paper Series 5137, The World Bank.

Malmendier U. and Tate G. (2009), Superstar CEOs, The Quarterly Journal of Economics, 124, 1593-1638.

Manski C. (1993), Identification of Endogenous Social Effects: The Reflection Problem, Review of Economic Studies, 60, 531-42.

Medvec V.H., Madey S.F. and Gilovich T. (1995), When Less is More: Counterfactual Thinking and Satisfaction among Olympic Medalists, Journal of Personality and Social Psychology, 69, 603-610.

Moulton B. (1986), Random Group Effects and the Precision of Regression Estimates, Journal of Econometrics, 32, 385-397.

Moxnes, E. and E. van der Heijden (2003), The effect of leadership in a public bad experiment, The Journal of Conflict Resolution, 47, 773-795.

Ostmann A., Wojtyniak B. and Beckenkamp M. (1997), Control and Sanctions may Destroy Commons. Experimental Results and Some Microanalytic Explications, ISMW Working Paper, vol. 7, University of Karlsruhe. 
Ostrom E. and Walker J.M. (1991), Communication in a Commons: Cooperation without External Enforcement. In: Palfrey, T.R. (Ed.), Laboratory Research in Political Economy. University of Michigan Press, Ann Arbor, 287-322.

Ostrom E., Walker J.M., Gardner R. (1992), Covenants with and without a Sword: Self-governance is Possible, American Political Science Review, 86, 404-417.

Potters J.J.M., Sefton M. and Vesterlund L., (2001), Why Announce Leadership Contributions? An Experimental Study of the Signaling and Reciprocity Hypotheses, Discussion Paper 2001-100, Tilburg University, Center for Economic Research.

Rabin M. (1993), Incorporating Fairness into Game Theory and Economics , American Economic Review, $83,1281-1302$.

Rogers E. (1962), Diffusion of Innovations, Glencoe: Free Press.

Sacerdote B. (2001), Peer Effects with Random Assignment: Results for Dartmouth Roommates, Quarterly Journal of Economics, 116, 681-704.

Sell J. and Wilson R. (1991), Levels of information and contributions to public goods, Social Forces, 70 , $107-124$.

Shang J. and Croson R. (2009), A Field Experiment in Charitable Contribution: The Impact of Social Information on the Voluntary Provision of Public Goods, Economic Journal, 119, 1422-1439.

Suls J., Martin R. and Wheeler L.(2002), Social Comparison: Why, With Whom, and With What Effect?, Current Directions in Psychological Science, 11, 159-163.

Vesterlund L. (2003), The informational value of sequential fundraising, Journal of Public Economics, 87, 627-657.

Vesterlund L. (2006), Why do people give?, in (Powell W. and Steinberg R.S., eds.), The Nonprofit Sector: A Research Handbook, 2nd Edition, 568-87, New Haven, CT: Yale University.

Vickrey W. (1962), One Economist's View of Philanthropy, in Philanthropy and Public Policy, 31-56, National Bureau of Economic Research, Inc.

Vyrastekova J., van Soest D. (2003), Centralized Common-pool Management and Local Community Participation, Land Economics, 79, 500-514.

Wood J. V. and Taylor K. L. (1991), Serving self-relevant goals through social comparison, in: Suls J. and Wills T. A. (eds.), Social comparison: Contemporary theory and Research, New Jersey: Lawrence Erlbaum Associates, Inc., Publishers, 23-49.

Wooldridge J. (2003), Cluster-Sample methods in Applied Econometrics, American Economic Review, 93, 133.

Yitzhaki S. (1982), Relative deprivation and economic welfare, European Economic Review, 17, 99-113. 
Tables and figures

Figure 1. Pair formation over rounds, an example
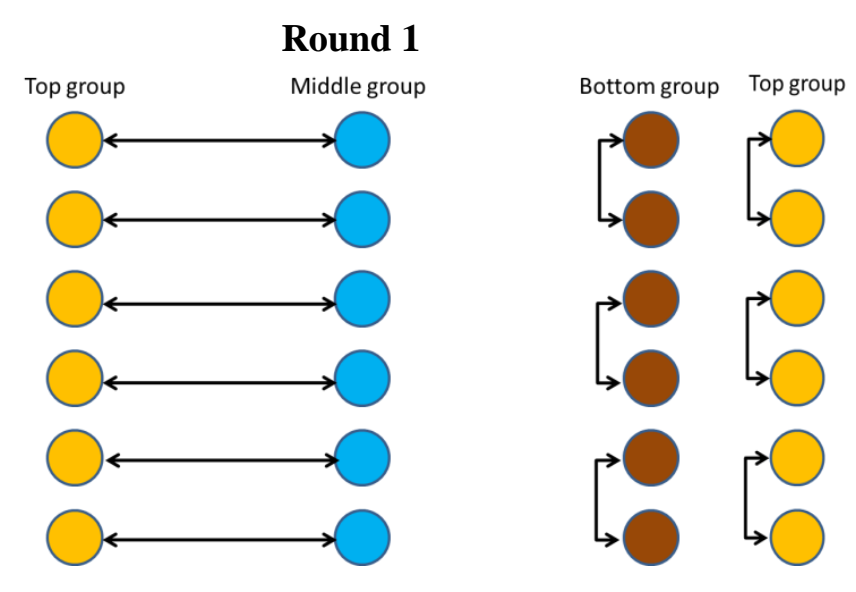

Round 2
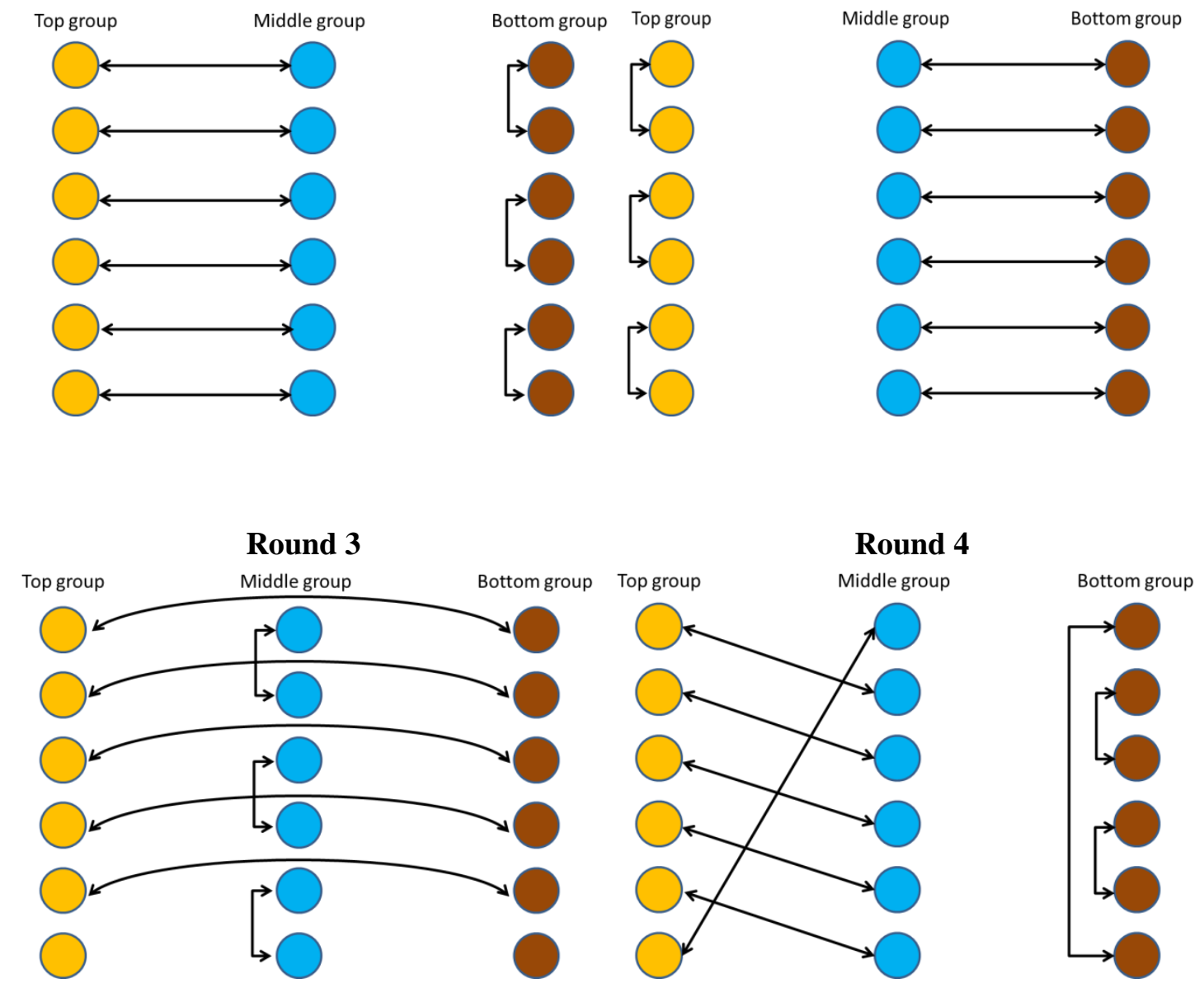
Figure 2. Contribution by absolute status, over type of authority salient

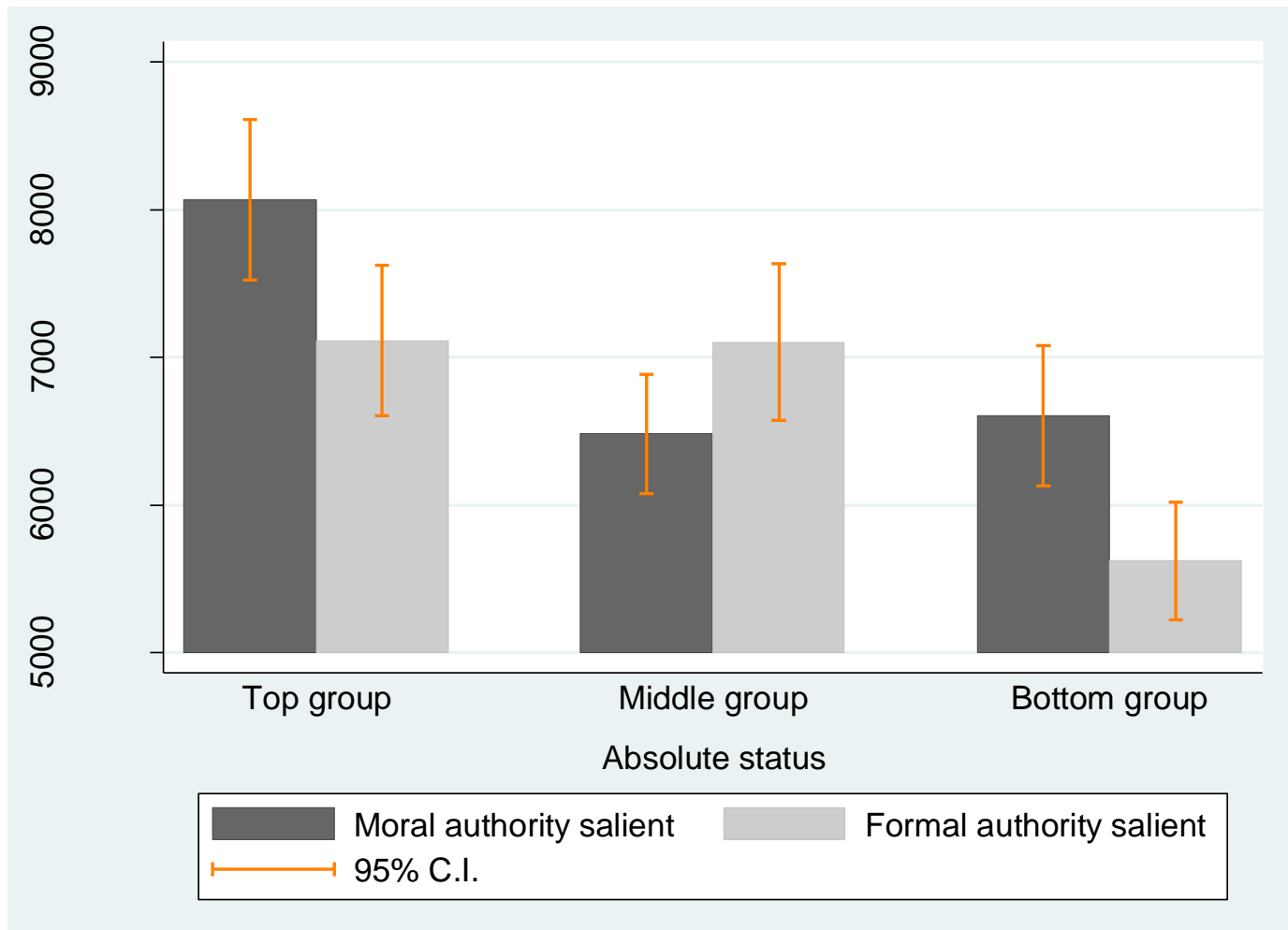

Figure 3. Revision amount and lag relative giving

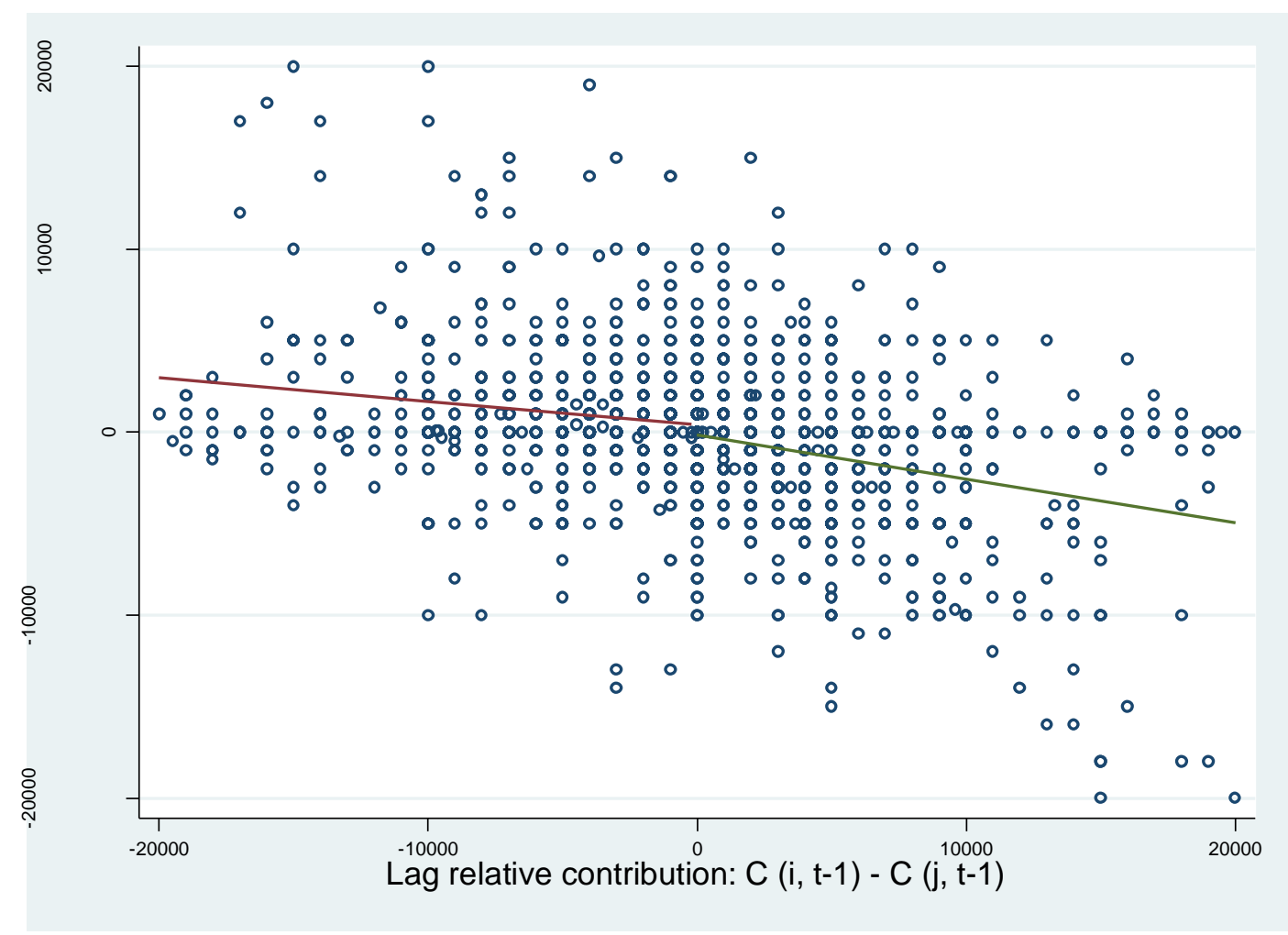


Figure 4. Within group differences in contribution

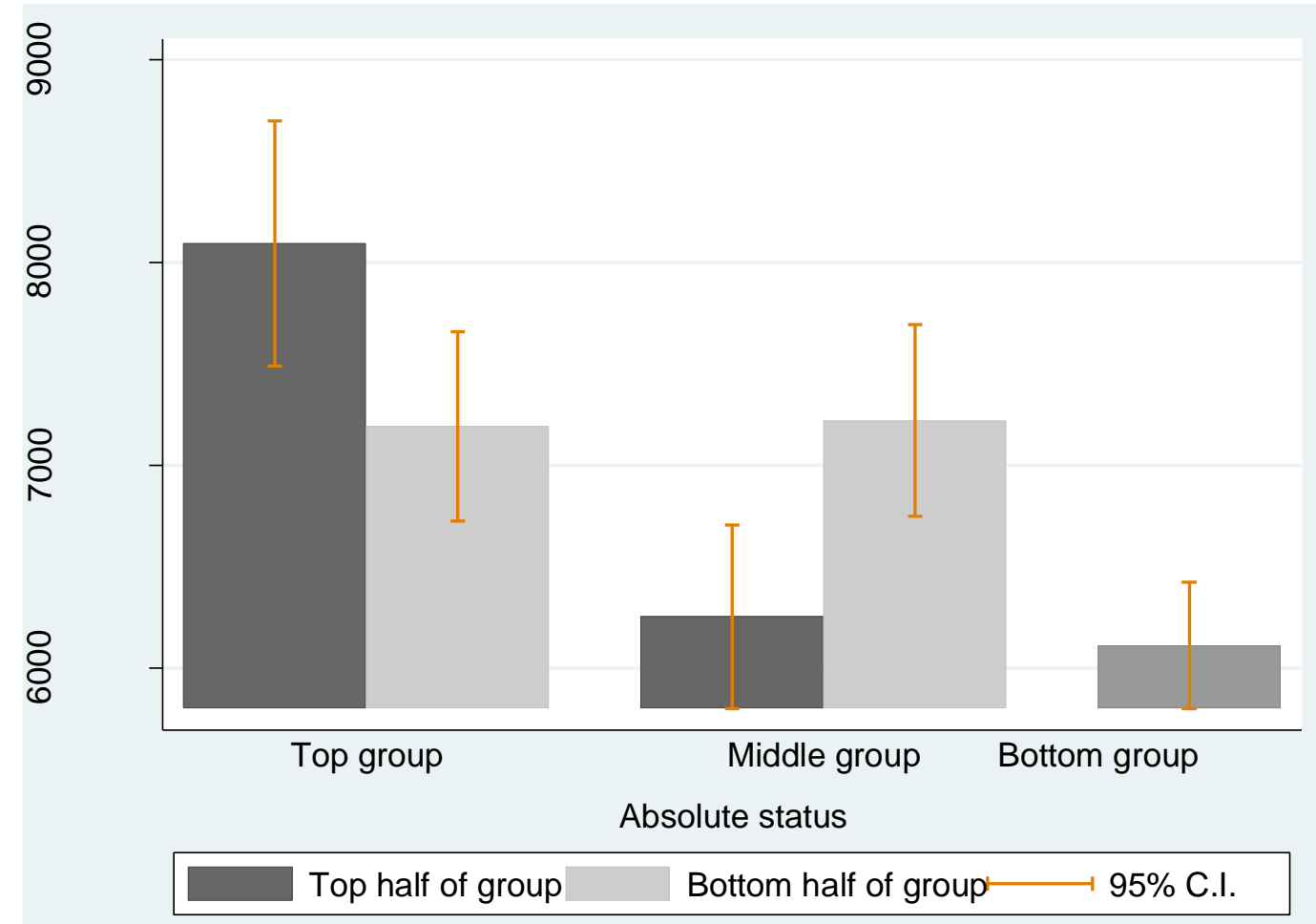


Table 1. Structure of session

\begin{tabular}{lcc}
\hline Decision & Round & Partner \\
\hline 1 & Private & \\
$2-3-4$ & 1 & A \\
$5-6-7$ & 2 & B \\
$8-9-10$ & 3 & C \\
$11-12-13$ & 4 & D \\
\hline
\end{tabular}

Table 2. Decision environment within rounds

\begin{tabular}{lccc}
\hline & $\begin{array}{c}\text { Partner's } \\
\text { rank known }\end{array}$ & $\begin{array}{c}\text { Partner's } \\
\text { previous } \\
\text { choice } \\
\text { known }\end{array}$ & $\begin{array}{c}\text { Partner will } \\
\text { know own } \\
\text { current } \\
\text { choice }\end{array}$ \\
\hline $1^{\text {st }}$ choice of round & $\mathrm{Y}$ & $\mathrm{N}$ & $\mathrm{Y}$ \\
$2^{\text {nd }}$ choice of round & $\mathrm{Y}$ & $\mathrm{Y}$ & $\mathrm{Y}$ \\
$3^{\text {rd }}$ choice of round & $\mathrm{Y}$ & $\mathrm{Y}$ & $\mathrm{N}$ \\
\hline
\end{tabular}

Table 3. Participants' characteristics

\begin{tabular}{lcc}
\hline \hline & Mean & Std. Dev. \\
& $\mathrm{n}=251$ & \\
\hline Age & 41.94 & {$[14.93]$} \\
Female (\%) & 39.84 & {$[.49]$} \\
Household size & 5.16 & {$[2.11]$} \\
No education (\%) & 10.36 & {$[.31]$} \\
Primary school (\%) & 41.83 & {$[.49]$} \\
Secondary school (\%) & 40.64 & {$[.49]$} \\
More than secondary school (\%) & 7.1 & {$[.26]$} \\
Individual income, previous week (Pesos) & 35.146 & {$[56,397]$} \\
Farming main source of income (\%) & 65.74 & {$[.48]$} \\
Farm size (he) & 2.34 & {$[6.55]$} \\
Owns livestock (\%) & 10.44 & {$[.31]$} \\
Suffered income loss due to environmental shock, previous year $(\%)$ & 78.09 & {$[.41]$} \\
Number of session participants who say ID is friend or relative & 3.65 & {$[3.19]$} \\
Number of community associations in which ID has a leadership role & .339 & {$[.60]$} \\
Member of ASPROCIG (\%) & 56.97 & {$[.49]$} \\
\hline
\end{tabular}


Table 4. Correlation between rankings

\begin{tabular}{lccc}
\hline & $\begin{array}{c}\text { Formal authority } \\
\text { ranking }\end{array}$ & $\begin{array}{c}\text { Moral authority } \\
\text { ranking }\end{array}$ & $\begin{array}{c}\text { Traditional } \\
\text { authority ranking }\end{array}$ \\
\hline \hline Formal authority ranking & 1 & & \\
Moral authority ranking & $0.351^{*}$ & 1 & \\
Traditional authority ranking & $0.130^{*}$ & $-0.149^{*}$ & 1.0000 \\
\hline Note: * significant at $10 \%, * *$ significant at $5 \%, *$ significant at $1 \%$ &
\end{tabular}

Table 5. Characteristics correlated with status

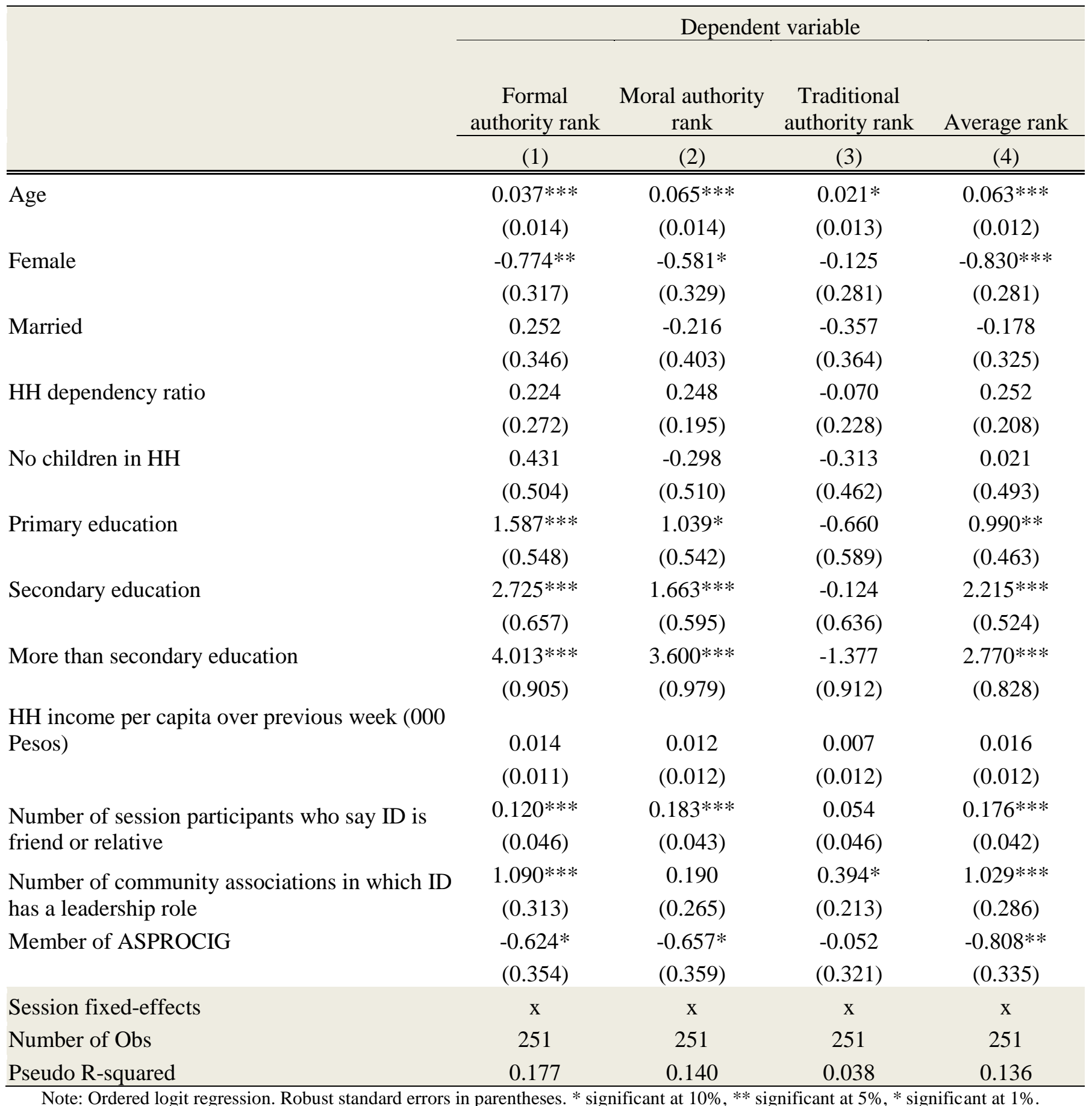


Table 6. Characteristics correlated with contribution

\begin{tabular}{lcc}
\hline & \multicolumn{2}{c}{ Dependent variable } \\
\cline { 2 - 3 } & & Avg C $_{\mathrm{i}}$ \\
& $\mathrm{C}_{\mathrm{i}}$ private & $($ Round 1-4) \\
\cline { 2 - 3 } & $(1)$ & $(2)$ \\
\hline \hline Age & -28.189 & -16.663 \\
Female & $(27.939)$ & $(23.112)$ \\
& 34.609 & -0.131 \\
Married & $(657.014)$ & $(539.432)$ \\
& 792.991 & 850.110 \\
HH dependency ratio & $(736.237)$ & $(596.784)$ \\
& -847.703 & -484.722 \\
No children in HH & $(565.130)$ & $(530.083)$ \\
Primary education & $-1827.128 *$ & -564.614 \\
& $(1011.780)$ & $(826.932)$ \\
Secondary education & -808.227 & 430.157 \\
& $(1220.035)$ & $(1117.748)$ \\
More than secondary education & -416.414 & 1348.755 \\
HH income per capita over previous week (000 Pesos) & $(1422.804)$ & $(1266.919)$ \\
Number of session participants who say ID is friend or & -231.710 & 1031.941 \\
relative & $(1909.158)$ & $(1756.634)$ \\
Number of community associations in which ID has a & 17.065 & 25.675 \\
leadership role & $(23.124)$ & $(21.199)$ \\
Member of ASPROCIG & -57.667 & 50.812 \\
R-squared & $(97.889)$ & $(82.372)$ \\
Numstant & 267.468 & 224.303 \\
Nession fixed-effects & $1441.665 * *$ & $1452.707 * *$ \\
& $(692.492)$ & $(572.798)$ \\
& $675.138 * *$ & 1691.230 \\
& $(2185.343)$ & $(1613.899)$ \\
Number of Obs & $\mathrm{x}$ & $\mathrm{x}$ \\
& 251 & 251 \\
& 0.293 & 0.409 \\
\hline
\end{tabular}

Note: Linear regression. Robust standard errors in parentheses. * significant at $10 \%$, ** significant at 5\%, * significant at $1 \%$. 
Table 7. Total pair contribution by pair composition

\begin{tabular}{lc}
\hline & $\begin{array}{c}\text { Dependent variable } \\
\text { Total pair contribution }\end{array}$ \\
\cline { 2 - 2 } Pair features at least one leader & $(1)$ \\
Constant & $1694.548 * * *$ \\
& $(469.787)$ \\
Session fixed-effects & $6402.576 * * *$ \\
Number of Obs & $(595.157)$ \\
Number of Clusters & $\mathrm{X}$ \\
R-squared & 1791 \\
\hline
\end{tabular}

Note: Random effect model with GLS estimator. Standard errors clustered at the individual level in parentheses. * significant at $10 \%, * *$ significant at $5 \%, *$ significant at $1 \%$.

Table 8. Leadership and individual contribution

\begin{tabular}{lcc}
\hline & \multicolumn{2}{c}{$\begin{array}{c}\text { Dependent variable } \\
\text { Contribution }\end{array}$} \\
\cline { 2 - 3 } & \multicolumn{2}{c}{$(2)$} \\
\hline Leader & $1112.831 * *$ & 850.697 \\
Constant & $(555.550)$ & $(635.719)$ \\
& $3314.099 * * *$ & $2358.563 *$ \\
Individual characteristics & $(442.800)$ & $(1422.506)$ \\
Session fixed-effects & & $\mathrm{X}$ \\
Number of Obs & $\mathrm{X}$ & $\mathrm{X}$ \\
Number of Clusters & 3262 & 3262 \\
R-squared & 251 & 251 \\
\hline
\end{tabular}

Note: Random effect model with GLS estimator. Standard errors clustered at the individual level in parentheses. Individual characteristics include: age, gender, education, number of community associations in which $i$ holds leadership roles, number of participants to the session who say that $i$ is a friend or relative, and ASPROCIG membership. * significant at $10 \%$, ** significant at $5 \%$, * significant at $1 \%$. 
Table 9. Higher relative status and contribution, individual fixed-effects

\begin{tabular}{lc}
\hline & $\begin{array}{c}\text { Dependent variable } \\
\text { Contribution }\end{array}$ \\
\hline Higher rank & $(1)$ \\
\cline { 2 - 2 } Constant & $286.177 * *$ \\
Individual fixed-effects & $6773.655^{* * *}$ \\
Number of Obs & $(71.115)$ \\
R-squared & $\mathrm{X}$ \\
\hline
\end{tabular}

Note: Linear regression with fixed-effect estimator. Robust standard errors in parentheses.

* significant at $10 \%, * *$ significant at $5 \%$, * significant at $1 \%$.

Table 10. Contribution, relative and absolute status

\begin{tabular}{|c|c|}
\hline & $\begin{array}{c}\text { Dependent variable } \\
\text { Contribution }\end{array}$ \\
\hline & $(1)$ \\
\hline Higher rank & $\begin{array}{c}1733.036 * * * \\
(414.924)\end{array}$ \\
\hline Leader & $\begin{array}{l}1205.207 * \\
(727.573)\end{array}$ \\
\hline Middle rank & $\begin{array}{c}623.835 \\
(551.528)\end{array}$ \\
\hline Higher rank*Leader & $\begin{array}{c}-1630.455^{* * *} \\
(442.896)\end{array}$ \\
\hline Higher rank*Middle rank & $\begin{array}{c}-1761.525 * * * \\
(463.007)\end{array}$ \\
\hline Constant & $\begin{array}{c}2120.446 \\
(1396.808)\end{array}$ \\
\hline Individual characteristics & $\mathrm{x}$ \\
\hline Session fixed effects & $\mathrm{x}$ \\
\hline Number of Obs & 3262 \\
\hline Number of Clusters & 251 \\
\hline R-squared & 0.305 \\
\hline
\end{tabular}

Note: Random effect model with GLS estimator. Standard errors clustered at the individual level in parentheses. Individual characteristics include: age, gender, education, number of community associations in which $i$ holds leadership roles, number of participants to the session who say that $i$ is a friend or relative, and ASPROCIG membership. * significant at $10 \%$, **significant at $5 \%$, * significant at $1 \%$. 
Table 11. Contribution among non-leaders, by partner's status

\begin{tabular}{lcc}
\hline & \multicolumn{2}{c}{ Dependent variable } \\
& $(1)$ & $(2)$ \\
\cline { 2 - 3 } & $-1165.471^{* *}$ & -903.635 \\
Non-Leader & $(554.387)$ & $(633.122)$ \\
Partner Leader & -103.179 & -102.798 \\
& $(154.774)$ & $(154.832)$ \\
Non Leader*Partner leader & 176.661 & 177.582 \\
& $(214.683)$ & $(214.948)$ \\
Constant & $4457.533^{* * *}$ & $3239.405^{* *}$ \\
& $(538.071)$ & $(1540.322)$ \\
Individual characteristics & & $\mathrm{x}$ \\
Session fixed-effects & $\mathrm{x}$ & $\mathrm{x}$ \\
Number of Obs & 3262 & 3262 \\
Number of Clusters & 251 & 251 \\
R-squared & 0.278 & 0.302 \\
\hline No: & & \\
\hline
\end{tabular}

Note: Random effect model with GLS estimator. Standard errors clustered at the individual level in parentheses. Individual characteristics include: age, gender, education, number of community associations in which $i$ holds leadership roles, number of participants to the session who say that $\mathrm{i}$ is a friend or relative, and ASPROCIG membership.

$*$ significant at $10 \%, * *$ significant at $5 \%, *$ significant at $1 \%$.

Table 12. Total pair contribution by type of leadership salient

\begin{tabular}{lc}
\hline & $\begin{array}{c}\text { Dependent variable } \\
\text { Total pair contribution }\end{array}$ \\
\cline { 2 - 2 } Moral leadership salient & $(1)$ \\
Constant & $2420.960 * * *$ \\
& $(601.010)$ \\
Session fixed-effects & $5043.476 * * *$ \\
Number of Obs & $(291.364)$ \\
Number of Clusters & $\mathrm{x}$ \\
R-squared & 1791 \\
\hline No: Ranto & 251 \\
\hline
\end{tabular}

Note: Random effect model with GLS estimator. Standard errors clustered at the individual level in parentheses. * significant at $10 \%, * *$ significant at $5 \%, *$ significant at $1 \%$. 
Table 13. Total pair contribution over time, by pair composition

\begin{tabular}{|c|c|c|}
\hline & \multicolumn{2}{|c|}{$\begin{array}{c}\text { Dependent variable } \\
\text { Total pair contribution }\end{array}$} \\
\hline & (1) & (2) \\
\hline \multirow[t]{2}{*}{ Pair features at least one leader } & 649.074 & 602.617 \\
\hline & $(538.900)$ & $(540.681)$ \\
\hline \multirow[t]{2}{*}{$\operatorname{Decision}(\mathrm{t})$} & -69.678 & $-382.337 * * *$ \\
\hline & $(45.396)$ & $(125.519)$ \\
\hline \multirow[t]{2}{*}{ Pair features at least one leader*Decision $(t)$} & $114.752 *$ & $121.034^{*}$ \\
\hline & $(62.103)$ & $(62.274)$ \\
\hline \multirow[t]{2}{*}{ Constant } & $6918.722 * * *$ & $10839.754 * * *$ \\
\hline & $(1196.125)$ & $(1871.020)$ \\
\hline Round fixed-effects & & $\mathrm{x}$ \\
\hline Session fixed-effects & $\mathrm{x}$ & $\mathrm{x}$ \\
\hline Number of Obs & 3010 & 3010 \\
\hline R-squared & 0.414 & 0.415 \\
\hline
\end{tabular}

Table 14. Contribution revision by lag relative contribution

\begin{tabular}{lcc}
\hline & \multicolumn{2}{c}{ Dependent variable } \\
& $\begin{array}{c}\text { Likelihood of upward } \\
\text { revision }\end{array}$ & $\begin{array}{c}\text { Likelihood of } \\
\text { downward revision }\end{array}$ \\
\cline { 2 - 3 } & $(1)$ & $(2)$ \\
\hline Gave more than partner in t-1 & $-0.154^{* * * *}$ & $0.219^{* * *}$ \\
Gave less than partner in t-1 & $(0.031)$ & $(0.032)$ \\
Constant & $0.215^{* * *}$ & $-0.171^{* * *}$ \\
& $(0.031)$ & $(0.032)$ \\
Individual fixed-effects & $0.288^{* * *}$ & $0.336 * * *$ \\
Number of Obs & $(0.026)$ & $(0.027)$ \\
R-squared & $\mathrm{x}$ & $\mathrm{x}$ \\
\hline Note: Linear probability fixed-effect model. Robust standard errors in & 0.122 & 2008 \\
\hline
\end{tabular}

Note: Linear probability fixed-effect model. Robust standard errors in parentheses. * significant at $10 \%$, ** significant at 5\%,

* significant at $1 \%$. 
Table 15. Leadership and contribution revision

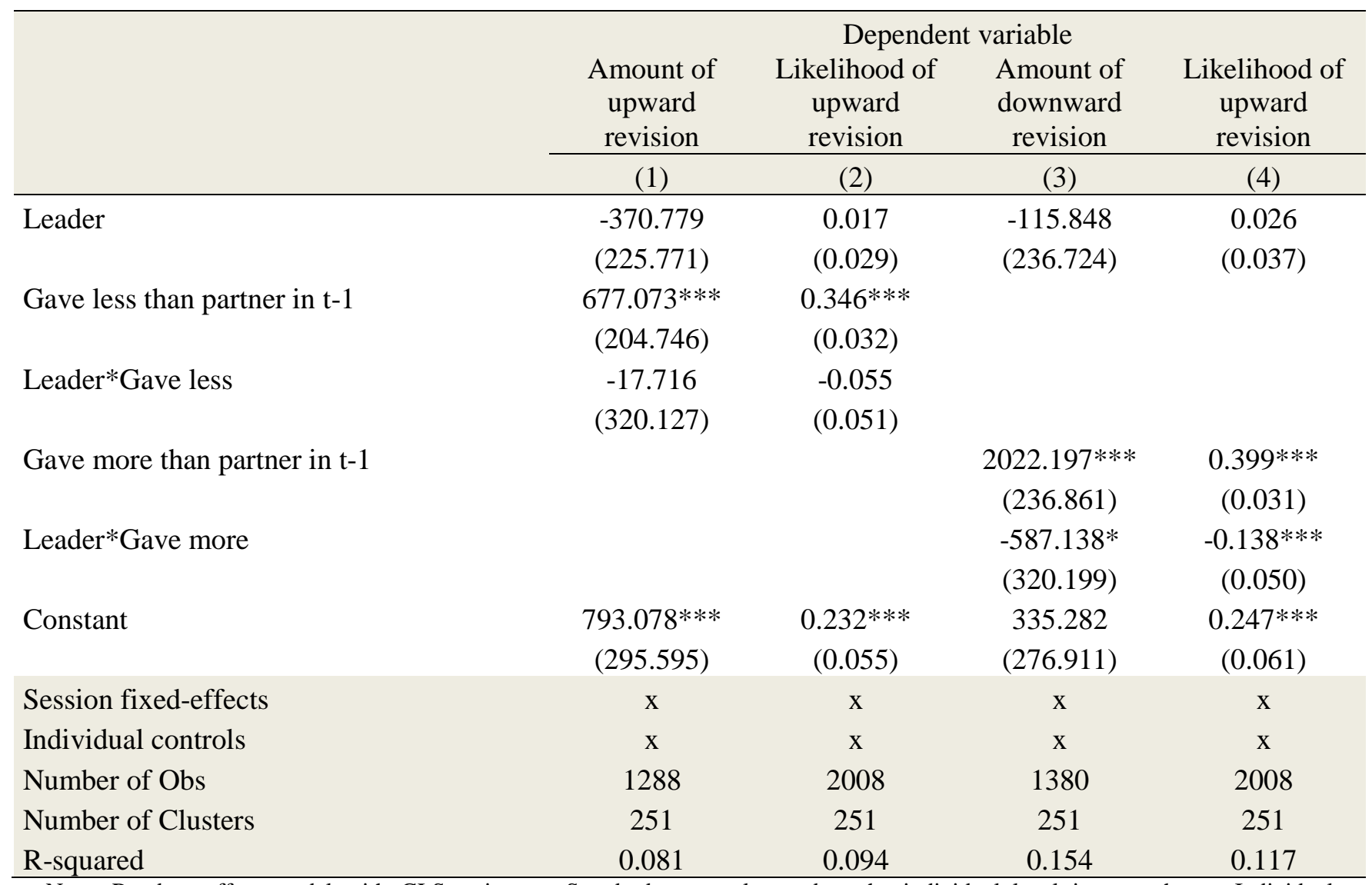

Note: Random effect model with GLS estimator. Standard errors clustered at the individual level in parentheses. Individual characteristics include: age, gender, education, number of community associations in which $i$ holds leadership roles, number of participants to the session who say that $i$ is a friend or relative, ASPROCIG membership, private contribution and lag partner contribution. * significant at $10 \%, * *$ significant at $5 \%, *$ significant at $1 \%$. 
Table 16. Higher relative status and contribution revision

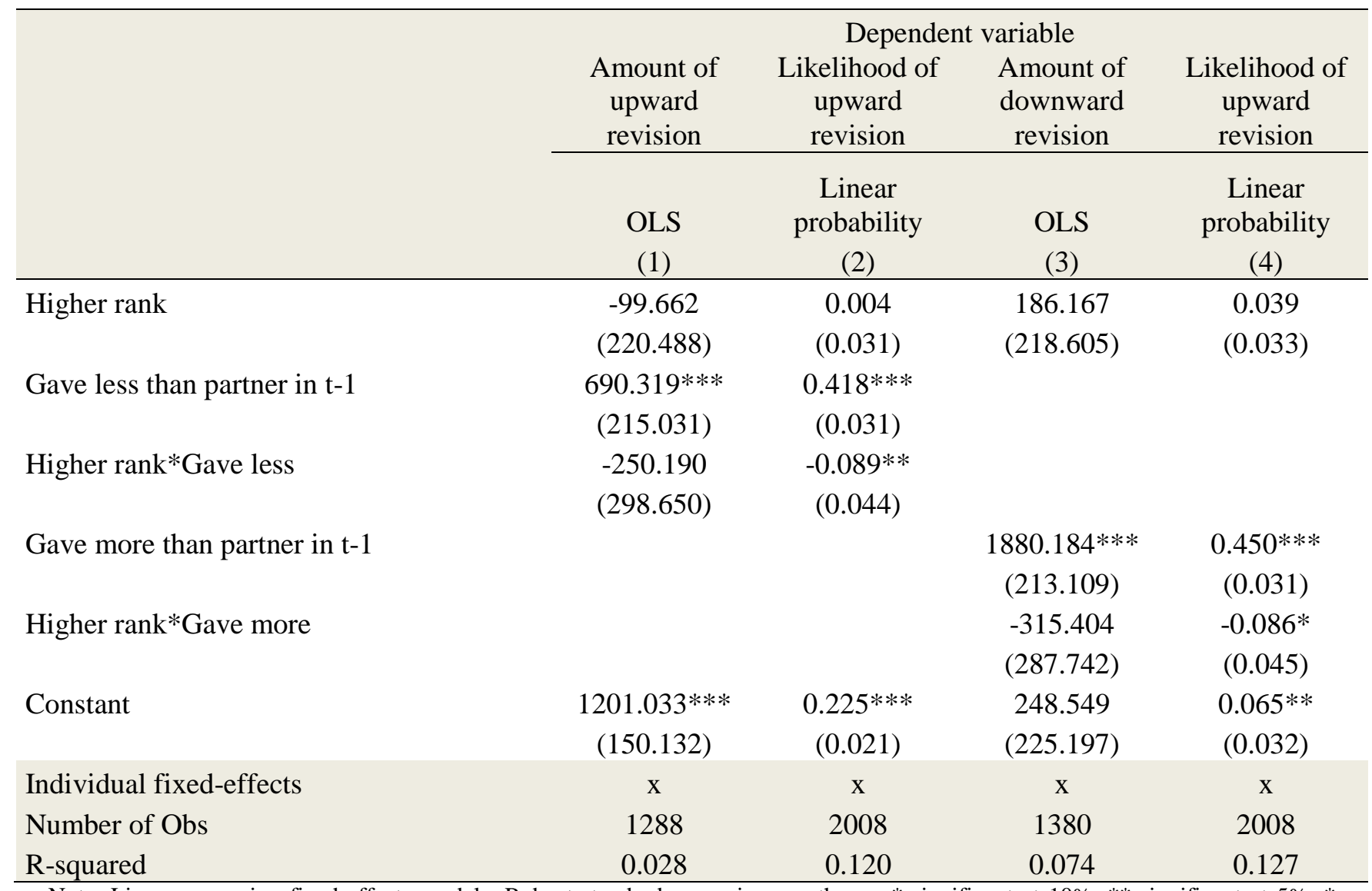

Note: Linear regression fixed-effects models. Robust standard errors in parentheses. $*$ significant at $10 \%, * *$ significant at $5 \%, *$ significant at $1 \%$. 
Table 17. Contribution revision of non-leaders, by partner's status

\begin{tabular}{|c|c|c|c|c|}
\hline & \multicolumn{4}{|c|}{ Dependent variable } \\
\hline & $\begin{array}{l}\text { Amount of } \\
\text { upward } \\
\text { revision }\end{array}$ & $\begin{array}{l}\text { Likelihood of } \\
\text { upward } \\
\text { revision }\end{array}$ & $\begin{array}{l}\text { Amount of } \\
\text { downward } \\
\text { revision }\end{array}$ & $\begin{array}{c}\text { Likelihood of } \\
\text { upward } \\
\text { revision }\end{array}$ \\
\hline & $(1)$ & (2) & (3) & (4) \\
\hline \multirow[t]{2}{*}{ Partner leader } & -4.423 & -0.016 & 105.589 & 0.035 \\
\hline & $(270.791)$ & $(0.035)$ & $(251.039)$ & $(0.034)$ \\
\hline \multirow[t]{2}{*}{ Gave less than partner in $\mathrm{t}-1$} & $479.797 *$ & $0.400 * * *$ & & \\
\hline & $(273.864)$ & $(0.038)$ & & \\
\hline \multirow{2}{*}{ Partner leader*Gave less } & 129.885 & 0.028 & & \\
\hline & $(360.380)$ & $(0.052)$ & & \\
\hline \multirow{2}{*}{ Gave more than partner in $\mathrm{t}-1$} & & & $2026.313 * * *$ & $0.471 * * *$ \\
\hline & & & $(285.923)$ & $(0.038)$ \\
\hline \multirow[t]{2}{*}{ Partner leader*Gave more } & & & 24.434 & -0.009 \\
\hline & & & $(363.435)$ & $(0.053)$ \\
\hline \multirow[t]{2}{*}{ Constant } & $1230.815^{* * *}$ & $0.221 * * *$ & 235.728 & 0.047 \\
\hline & $(178.563)$ & $(0.024)$ & $(280.841)$ & $(0.036)$ \\
\hline Individual fixed-effects & $\mathrm{x}$ & $\mathrm{x}$ & $\mathrm{x}$ & $\mathrm{x}$ \\
\hline Number of Obs & 848 & 1344 & 914 & 1344 \\
\hline R-squared & 0.028 & 0.130 & 0.084 & 0.154 \\
\hline
\end{tabular}

Table 18. Within-group differences in contribution

\begin{tabular}{lcc}
\hline & \multicolumn{2}{c}{ Dependent variable } \\
& \multicolumn{2}{c}{ Contribution } \\
\cline { 2 - 3 } & Top group & Middle group \\
\hline Top half group & $(1)$ & $(2)$ \\
\hline & -147.762 & -634.577 \\
Constant & $(597.453)$ & $(678.082)$ \\
& $-3069.344^{*}$ & 2734.291 \\
Session fixed-effects & $(1636.405)$ & $(2490.071)$ \\
Individual characteristics & $\mathrm{x}$ & $\mathrm{x}$ \\
Number of Obs & $\mathrm{x}$ & $\mathrm{x}$ \\
Number of Clusters & 664 & 671 \\
R-squared & 251 & 251 \\
\hline Ne: & 0.683 & 0.435 \\
\hline
\end{tabular}

Note: Random effect model with GLS estimator. Standard errors clustered at the individual level in parentheses. Individual characteristics include: age, gender, education, number of community associations in which i holds leadership roles, number of participants to the session who say that $i$ is a friend or relative, ASPROCIG membership, private contribution and lag partner contribution.

$*$ significant at $10 \%, * *$ significant at $5 \%$, * significant at $1 \%$. 
Table 19. Differences in contribution between bottom half of leaders' group and top half of middle group

\begin{tabular}{lc}
\hline & $\begin{array}{c}\text { Dependent variable } \\
\text { Contribution }\end{array}$ \\
\cline { 2 - 2 } Top half - Middle group & $(1)$ \\
Constant & 208.235 \\
& $(537.867)$ \\
Session fixed-effects & -538.975 \\
Individual characteristics & $(1768.173)$ \\
Number of Obs & $\mathrm{x}$ \\
R-squared & $\mathrm{x}$ \\
\hline
\end{tabular}

Note: Random effect model with GLS estimator. Standard errors clustered at the individual level in parentheses. Individual characteristics include: age, gender, education, number of community associations in which $\mathrm{i}$ holds leadership roles, number of participants to the session who say that $i$ is a friend or relative, and ASPROCIG membership, private contribution and lag partner contribution.

* significant at $10 \%, * *$ significant at $5 \%, *$ significant at $1 \%$.

Table 20. Friendship networks by status

\begin{tabular}{lccc}
\hline & & & \\
& Leaders & Not Leaders & p-value \\
\hline \hline Total number of friends & 5.16 & 5.47 & .398 \\
Number of friends in leaders' group & 2.19 & 2.28 & .655 \\
Number of friends not in leaders' group & 2.96 & 3.19 & .400 \\
\hline
\end{tabular}


Table 21. Contribution and friendship networks

\begin{tabular}{lcc}
\hline & \multicolumn{2}{c}{$\begin{array}{c}\text { Dependent variable } \\
\text { Contribution }\end{array}$} \\
\cline { 2 - 3 } & $(1)$ & $(2)$ \\
\hline Number of friends in leaders' group & -17.019 & -15.716 \\
Number of friends not in leaders' group & $(175.009)$ & $(183.417)$ \\
Partner is leader & -75.253 & -40.363 \\
& $(119.041)$ & $(118.901)$ \\
Number of friends in leaders' group*Partner leader & & -148.803 \\
& & $(318.702)$ \\
Number of friends not in leaders' group*Partner not & & -6.353 \\
leader & & $(104.141)$ \\
& & -53.455 \\
Constant & & $(70.273)$ \\
& & -1344.836 \\
Individual characteristics & -1410.246 & $(1431.204)$ \\
Session fixed-effects & $(1422.767)$ & $\mathrm{x}$ \\
Number of Obs & $\mathrm{x}$ & $\mathrm{x}$ \\
Number of clusters & $\mathrm{x}$ & 1999 \\
R-squared & 1999 & 251 \\
\hline
\end{tabular}

Note: Random effect model with GLS estimator. Standard errors clustered at the individual level in parentheses. Individual characteristics include: age, gender, education, number of community associations in which i holds leadership roles, number of participants to the session who say that $i$ is a friend or relative, ASPROCIG membership, private contribution, lag partner contribution and absolute status. * significant at 10\%, **significant at $5 \%$, * significant at $1 \%$. 
Table 22. Contribution and choice observability

\begin{tabular}{|c|c|c|}
\hline & \multicolumn{2}{|c|}{$\begin{array}{c}\text { Dependent variable } \\
\text { Contribution }\end{array}$} \\
\hline & $\begin{array}{l}\text { OLS } \\
(1)\end{array}$ & $\begin{array}{l}\text { OLS } \\
(2)\end{array}$ \\
\hline Choice observed & $\begin{array}{c}32.374 \\
(124.752)\end{array}$ & $\begin{array}{c}45.033 \\
(153.026)\end{array}$ \\
\hline Partner is leader & & $\begin{array}{c}16.551 \\
(192.977)\end{array}$ \\
\hline Choice observed*Partner is leader & & $\begin{array}{c}-37.832 \\
(264.339)\end{array}$ \\
\hline Constant & $\begin{array}{c}5964.803 * * * \\
(134.397)\end{array}$ & $\begin{array}{c}5959.084 * * * \\
(145.875)\end{array}$ \\
\hline Individual fixed-effects & $\mathrm{x}$ & $\mathrm{x}$ \\
\hline Number of Obs & 2007 & 2007 \\
\hline (Pseudo) R-squared & 0.029 & 0.029 \\
\hline
\end{tabular}


Appendix A

Table A1. Top 5 qualities of top-ranked individuals, by ranking type

\begin{tabular}{ll}
\hline \hline Formal authority ranking & \\
\hline Are active in the community, think about the common good & $22 \%$ \\
Have experience, knowledge and capacity to solve community problems & $15 \%$ \\
Are in good relationships with the mayor & $13 \%$ \\
Are leaders, influential people in the community & $8 \%$ \\
Are trusted, respected & $8 \%$ \\
Know the problems of the community & $8 \%$ \\
\hline \hline Moral authority ranking & $23 \%$ \\
\hline Speak well, have good argument, are persuasive & $21 \%$ \\
Are diplomatic, pacific, conciliatory & $12 \%$ \\
Have moral qualities: responsible, serious, honest, determined & $11 \%$ \\
Are in good relationships with community members & $10 \%$ \\
Have experience, knowledge, capacity to solve community problems & \\
\hline \hline Traditional authority ranking & $24 \%$ \\
\hline Are happy and funny & $19 \%$ \\
Are talented, have charisma & $15 \%$ \\
Are extroverted and enthusiastic & $14 \%$ \\
They have experience and skills, know many stories & $10 \%$ \\
\hline They are dynamic and creative & \\
\hline \hline
\end{tabular}

Note: Percentages are derived from the ratio between the number of times a certain quality was mentioned in the discussion and the total number of qualities mentioned. 